\title{
Collapse of I-section tapered beam-columns in medium-span steel frames: Finite element model validation and parameters influence evaluation
}

\author{
Ernesto Massaroppi Juniora* (D), Tiago César Zampaolo ${ }^{a}$ (i), Miguel Abambres ${ }^{b}$, Tiago Pinto Ribeiro ${ }^{c}$ \\ a Laboratorio de Mecânica Aplicada e Computacional, Departamento de Engenharia Mecânica, Escola de Engenharia de São Carlos (EESC), \\ Universidade de São Paulo (USP). Av. Trabalhador São-Carlense, 400. 13566-590 - São Carlos - SP, Brasil. E-mail: massarop@sc.usp.br, \\ cztiago@hotmail.com \\ ${ }^{b}$ Num3ros, Lisboa/Lisboa, Portugal, E-mail: amgg@mailfence.com \\ c Tal Projecto - Projetos, Estudos e Serviços de Engenharia, Lda. Av. Infante Santo, 70. 1350-180 - Lisboa/Lisboa, Portugal. E-mail: \\ tpribeiro@gmail.com
}

*Corresponding author

https://doi.org/10.1590/1679-78256050

\begin{abstract}
Tapered steel beams and columns have been increasingly used as primary load carrying members. The determination of their accurate ultimate capacity can only be achieved employing advanced numerical methods such as the finite element method (FEM). This paper presents a systematic study on the influence of FE model parameters on the ultimate load of I-section tapered beam-columns typically used in mediumspan steel frames. It aims the determination of optimal FE mesh size and sub-step number to be used during the arc-length scheme for the performance of an accurate, robust and efficient inelastic post-buckling parametric analysis (PA) as well as the evaluation of the parameters influence. Once validated the FE model, using hexahedral 8-node finite elements, FE edge sizes of 20, 25 and $30 \mathrm{~mm}$ and 10 sub-steps have been selected for use in the future PA. Several FE analyses were also carried out to evaluate how it is and quantify the influence of each of the parameters, leading to empirical equations with errors in the range of $-35 \%$ to $35 \%$ for equations without crossed terms and $-23 \%$ to $23 \%$ with first-order crossed terms.
\end{abstract}

\section{Keywords}

Finite element method, Inelastic post-buckling collapse, Mesh quality, Steel beam-column, Tapered member

\section{Graphical Abstract}

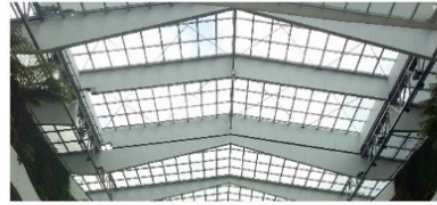

Structur

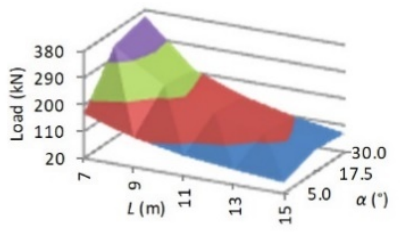

FEM Results

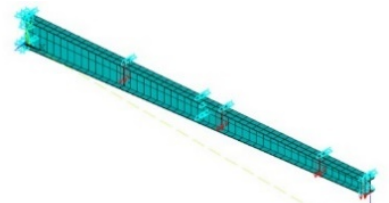

FE Model

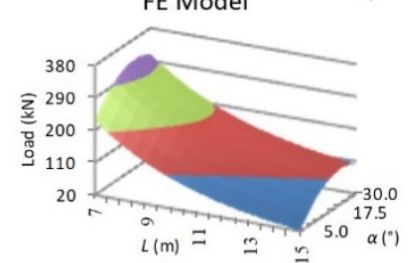

Approximation without crossed terms

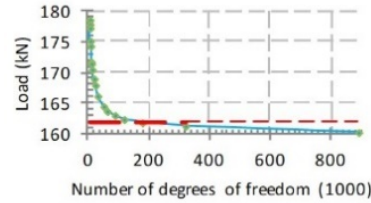

Determination of the FE Edge Size

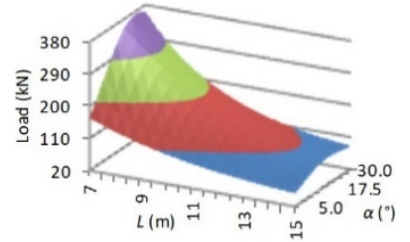

Approximation with crossed terms 


\section{INTRODUCTION}

Non-prismatic (tapered) members are widely used in modern steel construction in Civil, Mechanical and Aeronautical industries, mostly due to their i) structural efficiency, ii) functionality and iii) low fabrication costs (Zhang and Tong 2008). Figure 1 shows some typical applications of tapered steel beams in Civil Engineering structures.

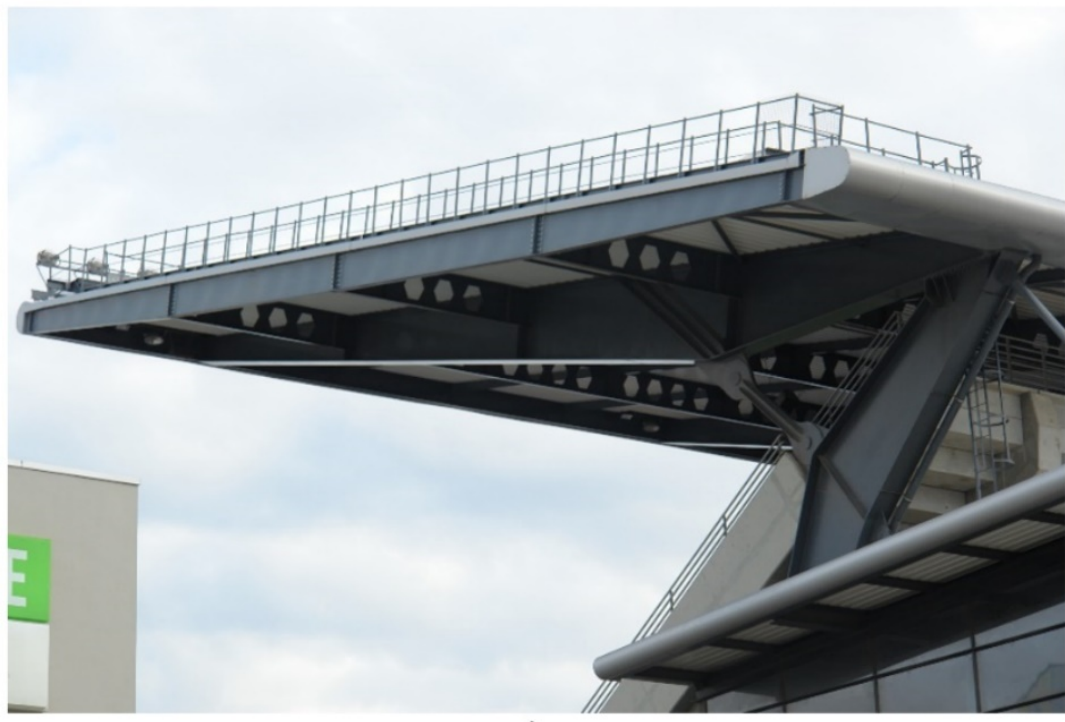

a)

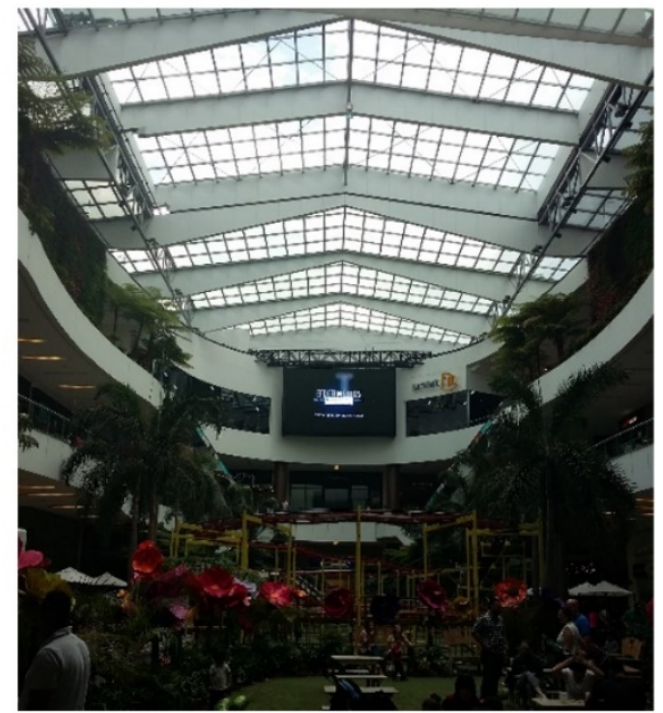

b)

Figure 1 Tapered steel roof beams:

a) football stadium (Coimbra, Portugal), b) shopping mall (Medellin, Colombia).

In order to take advantage of those benefits, accurate, simple and efficient design methods must be available. Nevertheless, it is well-known (Marques et al. 2012) that safety verifications in steel standards (CEN 2005, 2006, AISC 2010, SA 2016), mostly adapted from prismatic member rules, might be unsafe (up to $300 \%$ in some cases Bedynek et al. 2013), difficult to perform, and/or quite conservative (not taking advantage of the economy of nonprismatic members). A commonly adopted alternative to those methods, as recommended by design codes, is the use of advanced (physically and geometrically nonlinear) finite element analysis (FEA), which is obviously unfeasible in current design practice due to their time and know-how requirements (besides involving expensive FEA software). Although the large amount of research performed in the last few decades, either concerning i) numerical/analytical formulations (Asgarian and Soltani 2011, Trahair 2014, Mohri et al. 2015, Ghadban et al. 2017, Kim and Jang 2017, Balduzzi et al. 2017, Lee and Lee 2018), or ii) design methods (Marques et al. 2012, Zhang et al. 2013, Papp 2016), it is still imperative the development of groundbreaking (i.e., simultaneously accurate, easy-to-use, versatile, efficient and affordable) design rules/tools for tapered steel members.

In Civil Engineering, Artificial Neural Networks (ANN) have provided a convenient and often highly accurate solution to problems within all branches, appearing from publications statistics to be one of the great successes of computing (Flood 2008). The first journal article on civil engineering applications of neural networks was published by Adeli and Yeh (1989). The authors used a simple one-neuron model to the design of steel beams. Since then, many other applications of ANNs within all fields of Civil Engineering arose with increased complexity and sophistication (Adeli 2001).

Areas like i) buckling load prediction (Mukherjee et al. 1996, Sharifi and Tohidi 2014), ii) bearing capacity prediction (Chuang et al. 1998, Gandomi et al. 2013), iii) constitutive modeling (Jung and Ghaboussi 2006, Oeser and Freitag 2016), iv) structural reliability and/or optimization (Adeli and Park 1995, Papadrakakis and Lagaros 2016), or v) structural health monitoring (Masri et al. 2000, Min et al. 2012), have received special focus until today. Many successful ANN-based models have been proposed to assess the behavior of metals and structures, when composed by prismatic members (Sourmail et al. 2002, Guzelbey et al. 2006, Efstathiadesa et al. 2007, Lu et al. 2009, Sheidaii and Bahraminejad 2012, Xu et al. 2013, Tohidi and Sharifi 2015, 2016, Nazari et al. 2015, Banu and Rani 2016). Several works have revealed a huge decrease in computing time when comparing the proposed ANN model with the FEA counterpart, and without compromising accuracy - e.g., when estimating the temperature of a tubular truss under fire, Xu et al. (2013) concluded that the ANN computes the desired output 1800 times faster than FEA. Surprisingly, unlike for prismatic 
members, virtually no effort has been done to develop analysis and design methods for tapered metal members based on ANNs.

\section{OBJECTIVES}

The main objective of this research is to perform a large amount of FEA to have enough information to feed an ANN for an extensive parametric analysis (PA) and to determinate an empirical equation that can quickly predict the load capacity of an I-section tapered beam-column for designers who need to calculate new structures. When a large amount of FEA needs to be performed, as in this research, it should be noted that the savings of one second in each individual analysis allow savings of days in total CPU-time usage.

The accuracy and analysis time of the FE simulations are highly dependent on the modelling techniques adopted. The first objective of the work presented in this paper is the use of FEA techniques as well as the discussion of how to use them, which lead to a reduced simulation time that still guarantees the quality of the results. The second one is to carry out a small part of the analyses, but in sufficient quantity, to be able to determine the influence of each of the parameters on the collapse load of the I-beam.

To achieve these objectives, a FE model must first be created to guarantee the quality of the results. This model must represent the structure geometrically and have boundary conditions according to the real structure. The symmetry of the geometry and the boundary conditions, such as prescribed displacements and forces, must be used to decrease the size of the model to be simulated. The classic way to obtain reliable results is to perform a FE model validation by studying the influence of the mesh size on the results. Besides, it is important to define the conditions under which analyses will be carried out. Then, the sequence in which analyses need to be performed as well as the number of substeps to be used during the arc-length scheme in the non-linear analyses need to be determined. After defining how the analyses should be performed, representative cases of the parameters values combinations must be chosen to verify the influence of each one of them on the results.

This paper addresses details and important conclusions about how the mesh validation procedures and load substep were carried out as well as the analysis of the parameters influence for the definition of an empirical equation were performed before the onset of the PA, all performed using the FE package ANSYS (Ansys Inc 2014).

\section{DESCRIPTION OF THE FINITE ELEMENT ANALYSIS}

The determination of the collapse load due to structural instability by the FEM is carried out in four basic steps: i) initially, a linear static analysis of the structure subjected to a unity load is performed to determine the stiffness matrix and the unit vector load; ii) then the elastic buckling analysis is carried out, given by the solution of the eigenproblem, in which the buckling shape is given by the eigenvector and the critical load by the eigenvalue of the stiffness matrix; iii) a proportion of the buckling shape is seen as a geometrical imperfection and is used to change the geometry of the structure and iv) finally, a quasi-static elastoplastic (non-linear) analysis is performed with a stop criterion, which can be the singularity of the stiffness matrix or a maximum displacement of a specif point in the structure. The collapse load is taken as the maximum load value obtained in the last analysis.

Within this context, the work presented herein is part of an ongoing investigation that aims to propose an ANN-based design scheme (determination of elastic buckling and collapse loads) for I-section tapered beamcolumns (see Figure 2) used in typical medium-span steel frames, usually adopted in structural systems for industrial buildings, transportation stations and hubs, sporting facilities and multifunctional halls. The loading conditions presented in the figure represent the usual cases of this type of structure. The vertical symmetrical load occurs when the structure is subjected to its weight and other loads placed on it, such as the accumulation of snow for example. Symmetrical orthogonal loading is typical of frontal wind loading, while asymmetric loading is typical of lateral wind.

For that purpose, the first step consists in the performance of an extensive parametric FEA for the computation of i) elastic buckling and ii) ultimate bearing capacity loads. The PA involves twelve independent (input) variables, as defined in Table 1. For the sake of completeness of the information, Table 1 shows fourteen variables, but both the Modulus of Elasticity and the Tangente Module can only assume a single value. All combinations of input variable values will be taken for the PA, resulting in a total of 295245 distinct beam-columns to be simulated. 

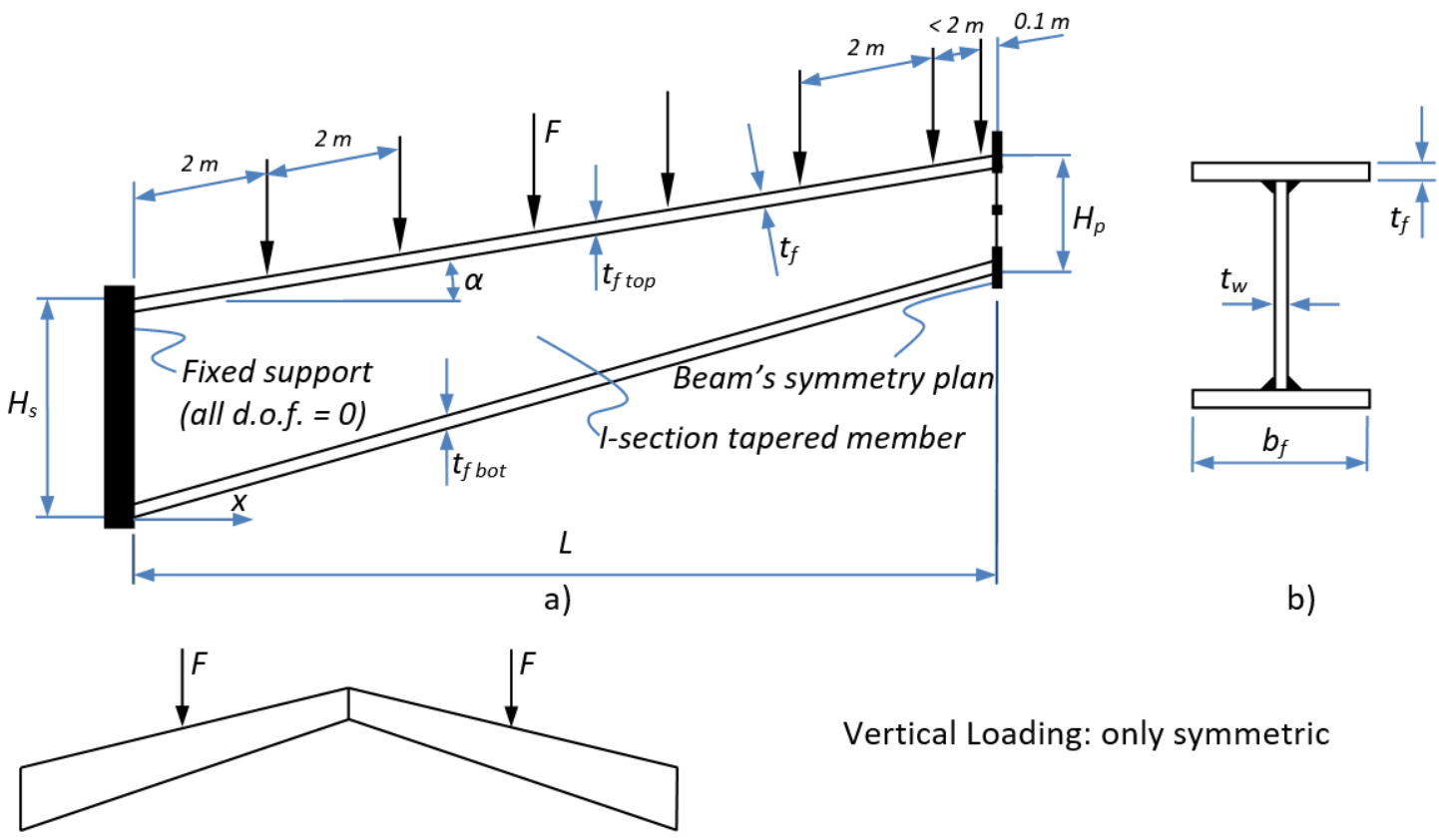

b)

c)

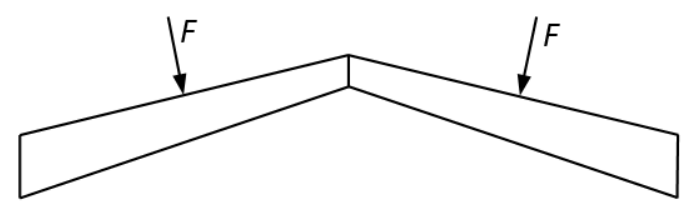

d)

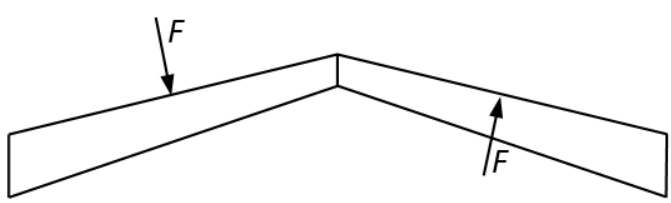

e)

Figure 2 I-section beam-columns adopted: a) geometrical parameters, b) cross-section, c) vertical symmetric loading, d) orthogonal symmetric loading, e) orthogonal asymmetric loading.

Table 1 Variables and his values involved in the FE-based parametric analysis.

\begin{tabular}{|c|c|c|c|c|c|c|c|c|}
\hline \multicolumn{4}{|c|}{ INPUT VARIABLES } & \multicolumn{5}{|c|}{ POSSIBLE VALUES } \\
\hline \multirow[t]{7}{*}{ Geometry } & Length & $L$ & (m) & 7 & 9 & 11 & 13 & 15 \\
\hline & Angle & $\alpha$ & $\left({ }^{\circ}\right)$ & 5.0 & 17.5 & 30.0 & & \\
\hline & Height on fixed support & $H_{s}$ & (m) & 0.490 & 0.795 & 1.100 & & \\
\hline & Height in the sym. plane & $H_{p}$ & (m) & 0.230 & 0.420 & 0.610 & & \\
\hline & Flange width & $b_{f}$ & (m) & 0.180 & 0.225 & 0.270 & & \\
\hline & Flange thickness & $t_{f}$ & (m) & 0.010 & 0.020 & 0.030 & & \\
\hline & Web thickness & $t_{w}$ & (m) & 0.008 & 0.012 & 0.016 & & \\
\hline $\begin{array}{l}\text { Geometrical } \\
\text { Imperfection }\end{array}$ & Global geom. imperf. & $\delta_{g}$ & (m) & 0 & $L / 2000$ & $L / 1000$ & & \\
\hline $\begin{array}{l}\text { Membrane } \\
\text { Residual } \\
\text { Stresses }\end{array}$ & Distribution model & & & ECCS (1984) & $\begin{array}{l}\text { Swedish code } \\
\text { (BSK 99, 2003) }\end{array}$ & $\begin{array}{l}\text { Wang et al. } \\
\text { (2012) }\end{array}$ & & \\
\hline \multirow{3}{*}{$\begin{array}{l}\text { Material (bi- } \\
\text { linear law) }\end{array}$} & Yield stress & $S_{y}$ & $\left(\mathrm{~N} / \mathrm{m}^{2}\right)$ & $290 \mathrm{E}+6$ & $335 E+6$ & $380 E+6$ & & \\
\hline & Modulus of Elasticity & $E$ & $\left(\mathrm{~N} / \mathrm{m}^{2}\right)$ & $210 E+9$ & & & & \\
\hline & Tangent Module & $E / E_{t}$ & & 10000 & & & & \\
\hline \multirow[t]{2}{*}{ Loading } & Symmetry & & & symmetric & asymmetric & & & \\
\hline & Force direction & & & vertical & orthogonal & & & \\
\hline
\end{tabular}




\section{PRELIMINARY RESULTS}

\subsection{Mesh size and number of sub-steps}

Since member flanges and webs cannot be considered thin-walled for all cases to be simulated in the PA, hexahedral 8-nodes FEs, SOLID185 in Ansys Inc. (2014), were adopted. In order to determinate the appropriate mesh size, it is necessary to choose some combinations of the parameters shown in Table 1, since this analysis cannot be performed for all possible parameter combinations. It is known that the time of a FEA grows with the number of degrees of freedom. Therefore, for a given geometry, the use of the largest possible finite element edge size leads to the smaller number of elements, nodes, and degrees of freedom and, consequently, less analysis time. Within this point of view three beamcolumns features were chosen: i) small, in which each parameter assumes the lowest value present in Table 1, ii) large, in which each parameter assumes the highest value, and iii) intermediate, in which the parameters are given by average values. These features were used to obtain the ideal mesh size for this investigation, i.e. yielding accurate results in the shortest time possible. At this stage, no residual stresses and only the vertical symmetric loading were used. With this option, only nine of the twelve parameters remain variable, and the featuring used in each of the three cases are shown in Table 2. The FE model of these three cases is shown in Figure 3. The beam images are approximately on the same scale. The dashed lines in part a) of the figure are horizontal and vertical and represent the longitudinal median plane. Part b) is a zoom of the region close to the symmetry plane.

Table 2 Beam-columns featuring.

\begin{tabular}{cccc}
\hline feature & small & intermediate & large \\
\hline$L(\mathrm{~m})$ & 7 & 11 & 15 \\
$\alpha\left(^{\circ}\right)$ & 5.0 & 17.5 & 30.0 \\
$H_{s}(\mathrm{~m})$ & 0.490 & 0.795 & 1.100 \\
$H_{p}(\mathrm{~m})$ & 0.230 & 0.420 & 0.610 \\
$b_{f}(\mathrm{~m})$ & 0.180 & 0.225 & 0.270 \\
$t_{f}(\mathrm{~m})$ & 0.010 & 0.020 & 0.030 \\
$t_{w}(\mathrm{~m})$ & 0.008 & 0.012 & 0.016 \\
$\delta_{g}(\mathrm{~m})$ & $L / 2000$ & $L / 1000$ & $L / 500$ \\
$S_{y}\left(\mathrm{~N} / \mathrm{m}^{2}\right)$ & $290 \mathrm{E}+06$ & $335 \mathrm{E}+06$ & $380 \mathrm{E}+06$ \\
\hline
\end{tabular}

iii)

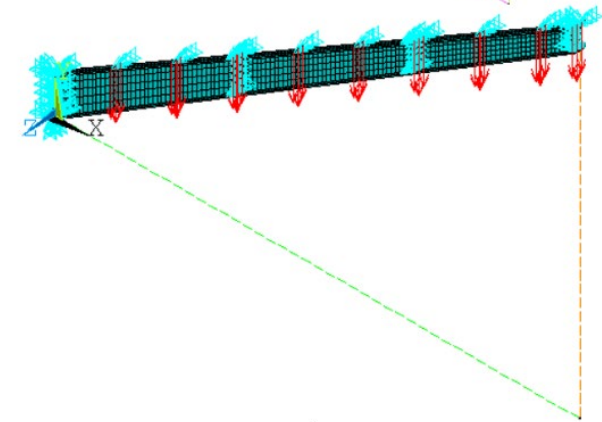

a)
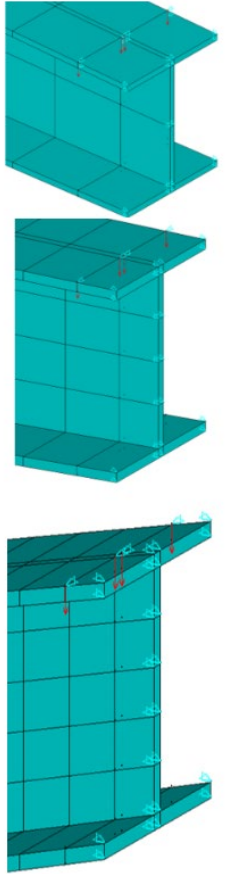

b)

Figure 3 I-section beam-columns model adopted: a) perspective view, b) region close to the symmetry plane:

i) small case, ii) intermediate case, iii) large case. 
Due to the small flange and web thickness, only one FE was employed through it. The remaining (and equal) FE edge sizes were made variable. For the three cases, analyses with FE edge size from $10 \mathrm{~mm}$ to $150 \mathrm{~mm}$ were performed. The results were plotted in Figure 4 which shows the collapse load as a function of a) the number of degrees of freedom of the model and $b$ ) the FE edge size. A horizontal dashed red line was then drawn at the collapse load value $1 \%$ above that obtained for the $10 \mathrm{~mm}$ FE edge size case. It can be seen that in the three cases the collapse load obtained for FE edge size up to $30 \mathrm{~mm}$ are bellow this line. Therefore, the use of FE, with any of the simulated dimensions, below the dashed line leads to similar results, which can be considered "exact", as they are in accordance with the criteria used to adopt this value in parametric analyses. It was then decided to use $30 \mathrm{~mm}$ edges that implies in a smaller number of degrees of freedom and consequently a shorter simulation time. When looking at part b) of the figure, the red dashed line can only be seen as a reference value. However, when looking at part a) of the same figure, it is clear that below the line there is an almost null gradient of the collapse load, while above this value there is a gradient close to infinity. This change in the value of the curve gradient (inflection) is also a good indicator of the FE edge size to be used.

Altair HyperWorks (2011) recommends that the FE aspect ratio is greater than 0.33 , but the minimum value of 0.4 was adopted in this work. Thus, whenever the $30 \mathrm{~mm}$ of FE edge does not guarantee that minimum, the exact values leading to a 0.4 aspect ratio are employed $-20 \mathrm{~mm}$ whenever the web thickness equals $8 \mathrm{~mm}$, and $25 \mathrm{~mm}$ otherwise if a flange thickness of $10 \mathrm{~mm}$ is used.

Once fixed the FE edge size, the number of sub-steps used per load step of the iterative arc-length scheme (employed to obtain the equilibrium path), was set as a parametric variable taking distinct values from 1 to 20 for each member - a reliable FE mesh characterized by an element edge of $20 \mathrm{~mm}$ was used in all cases. In the end, it was decided to adopt 10 sub-steps, since it is the value leading to the shortest analysis time and less than $1 \%$ difference for the ultimate load values obtained with 20 sub-steps (assuring precise results).

i)

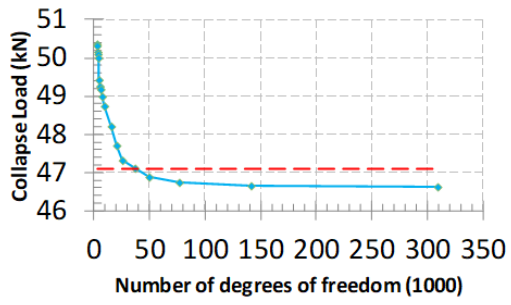

ii)

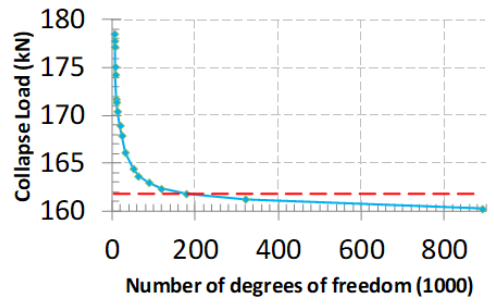

iii)

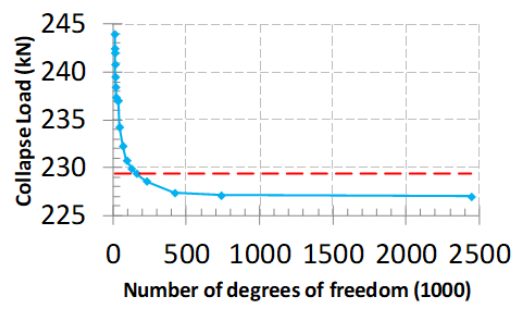

a)
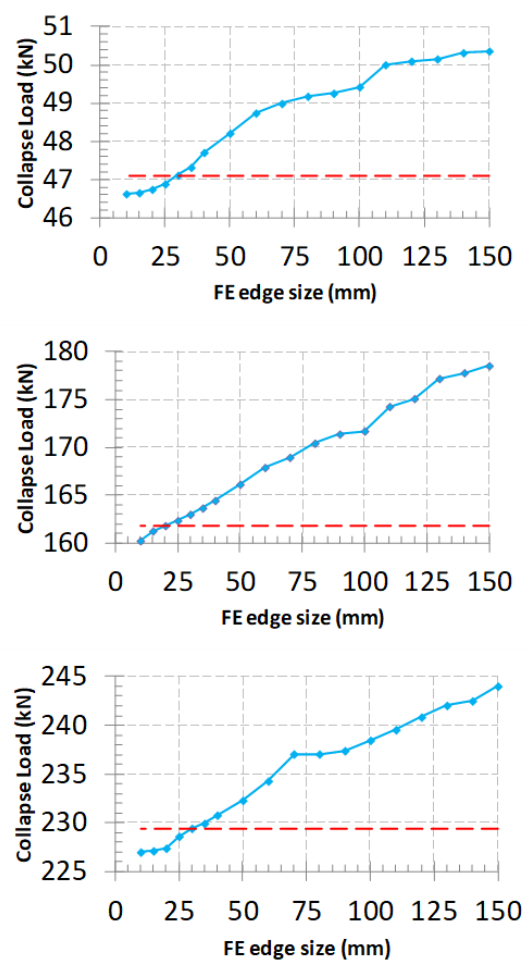

b)

Figure 4 Collapse Load (kN) as a function of the: a) the number of degrees of freedom (1000), b) FE edge size (mm): i) small case, ii) intermediate case, iii) large case.

\subsection{Parameter influence}

\subsubsection{Finite Element Analysis}

Having defined the FE size to be used, it starts by analysing the joint influence on the collapse load of two of the parameters shown in Table 2, while the other parameters remain constant. As there are nine parameters, five analysis groups are necessary and one of the parameters will be present in two of the groups. The following analyses were chosen 
for each of the three cases (small, intermediate and large): Collapse Load as a function of i) Length and Angle, ii) Length and Flange width, iii) Height on fixed support and Height in the symmetry plane, iv) Flange thickness and Web thickness and v) Yield stress and Geometrical imperfection.

Figures 5 to 9 show these results. Each of the figures is organized as follows: column a) presents the Collapse Load as a function of parameter 1 for different values of parameter 2, column c) presents the same results by inverting parameters 1 and 2 and column b) shows a three-dimensional graph of the Collapse Load as a function of the two parameters simultaneously. Line i) shows the results of the small case, line ii) of the intermediate and line iii) of the large one.

i)

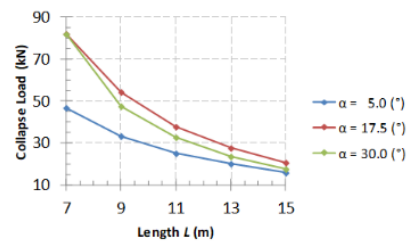

ii)

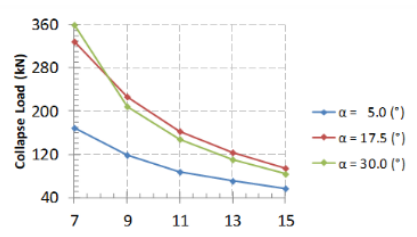

iii)

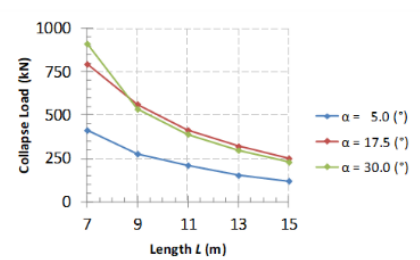

a)

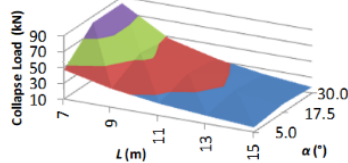

= 10-30 $=30-50=50-70=70-90$

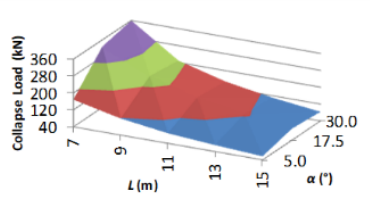

$=40-120=120-200=200-280=280-360$

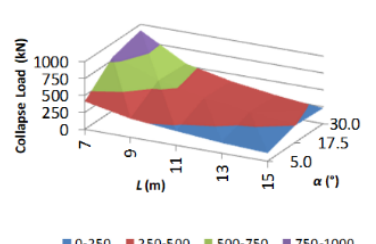

b)
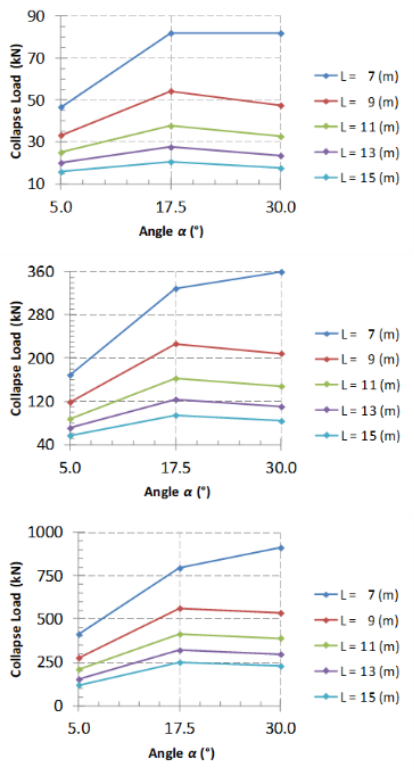

c)

Figure 5 Collapse Load $(\mathrm{kN})$ as a function of the: a) Length $(\mathrm{m}), \mathrm{b})$ Length $(\mathrm{m})$ and Angle $\left({ }^{\circ}\right)$, c) Angle $\left({ }^{\circ}\right)$ : i) small case, ii) intermediate case, iii) large case.

i)

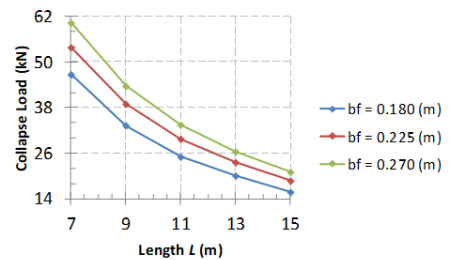

ii)

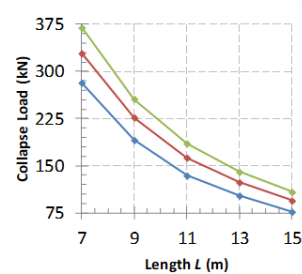

$\rightarrow-b f=0.180(\mathrm{~m})$ $\rightarrow-b f=0.225(\mathrm{~m})$

iii)

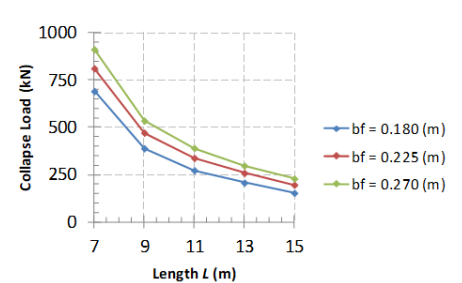

a)
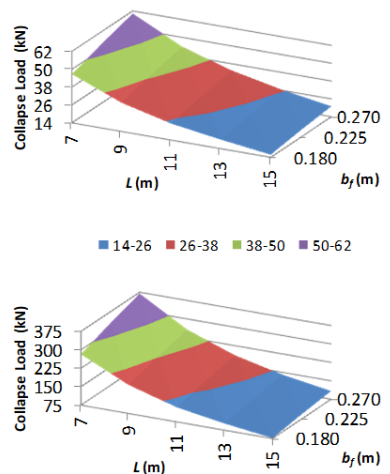

$=75-150=150-225=225-300=300-375$

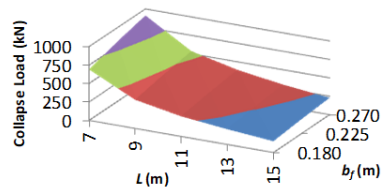

$=0-250=250-500 \quad=500-750 \quad=750-1000$

b)
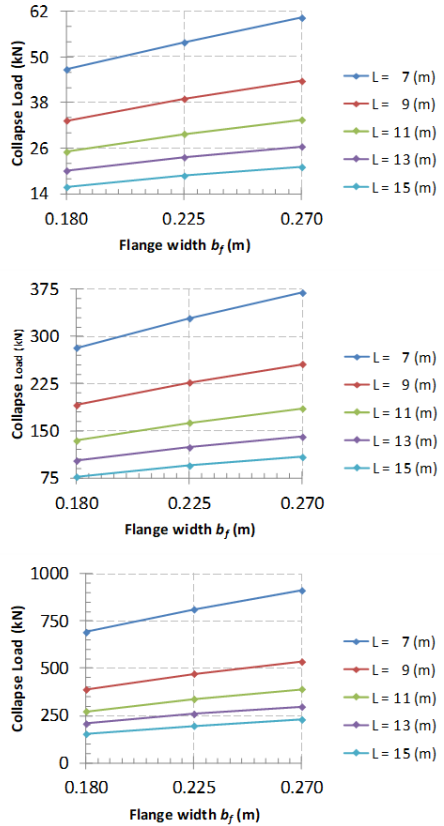

c)

Figure 6 Collapse Load $(\mathrm{kN})$ as a function of the: a) Length $(\mathrm{m}), \mathrm{b})$ Length $(\mathrm{m})$ and Flange width $(\mathrm{m})$, c) Flange width (m): i) small case, ii) intermediate case, iii) large case. 
i)

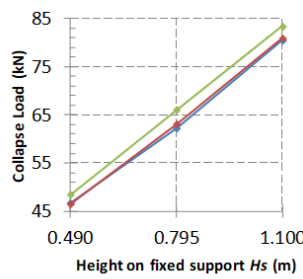

$\rightarrow \mathrm{Hp}=0.230(\mathrm{~m}$ $\rightarrow-\mathrm{Hp}=0.420(\mathrm{~m})$

ii)

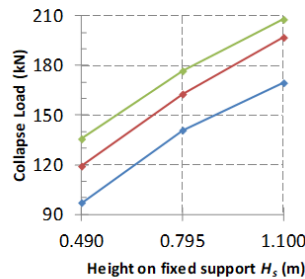

$\rightarrow \mathrm{Hp}=0.230(\mathrm{~m})$ $\rightarrow-\mathrm{Hp}=0.420(\mathrm{~m})$ Height on fixed support $H_{s}(\mathrm{~m})$

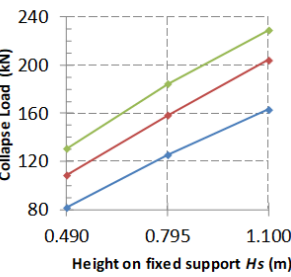

a)

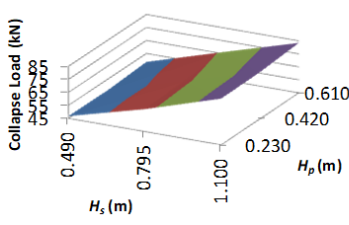

$45-55=55-65=65-75=75-85$

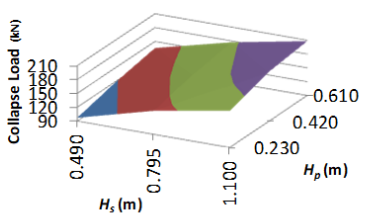

$=90-120=120-150=150-180 \square 180-210$

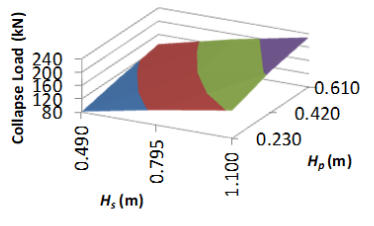

$=80-120=120-160=160-200=200-240$

b)
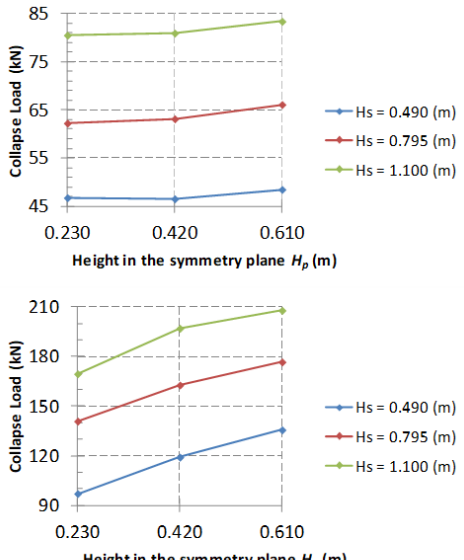

Height in the symmetry plane $H_{p}(\mathrm{~m})$

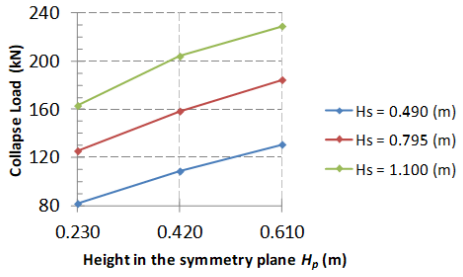

c)

Figure 7 Collapse Load $(\mathrm{kN})$ as a function of the: a) Height on fixed support $(\mathrm{m})$,

b) Height on a fixed support $(\mathrm{m})$ and Height in the symmetry plane $(\mathrm{m}), \mathrm{c})$ Height in the symmetry plane $(\mathrm{m})$ : i) small case, ii) intermediate case, iii) large case.

i)

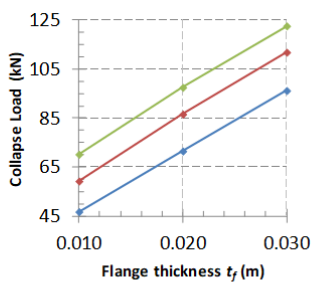

$\rightarrow \mathrm{tw}=0.008(\mathrm{~m})$ $\rightarrow \mathrm{tw}=0.012(\mathrm{~m})$

ii)

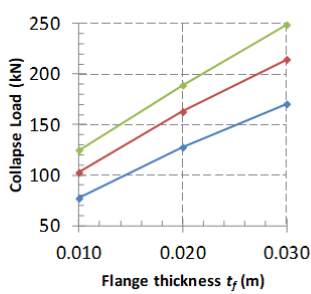

$\rightarrow \mathrm{tw}=0.008(\mathrm{~m})$ $\rightarrow-\mathrm{tw}=0.012(\mathrm{~m})$ $\rightarrow \mathrm{tw}=0.016(\mathrm{~m}$

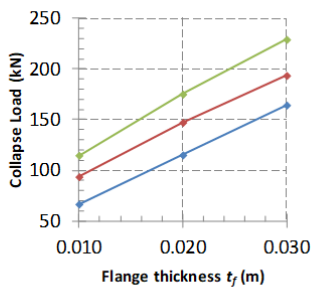

a)

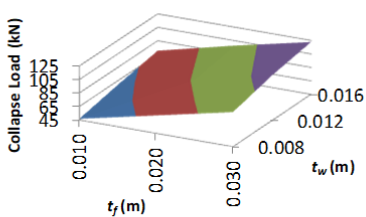

- 45-65 $=65-85 \quad=85-105 \quad=105-125$

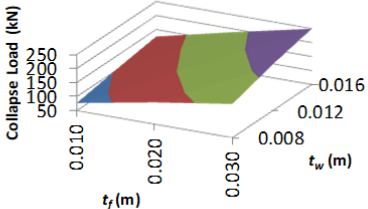

- $50-100=100-150=150-200=200-250$

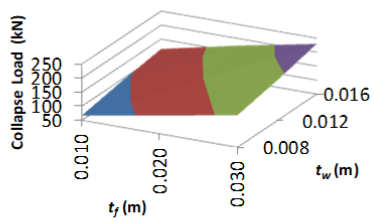

$=50-100=100-150 \quad=150-200 \quad=200-250$

b)
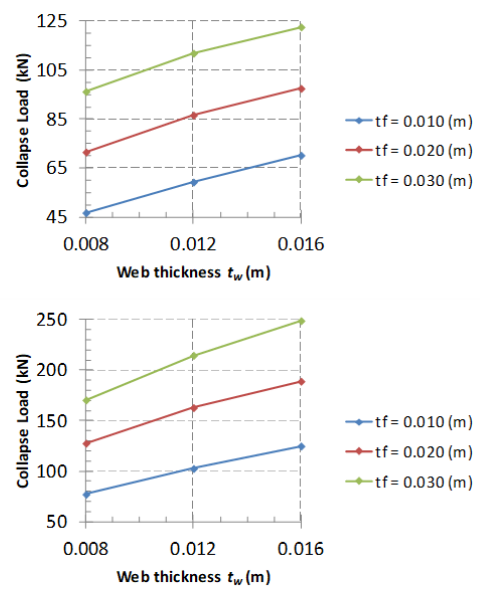

$\rightarrow-t f=0.010(\mathrm{~m})$ $\rightarrow-\mathrm{tf}=0.020(\mathrm{~m})$ $\rightarrow-t f=0.030(m)$

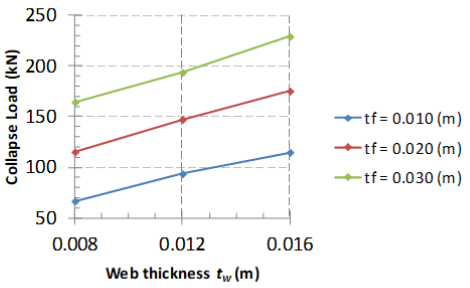

c)

Figure 8 Collapse Load $(\mathrm{kN})$ as a function of the: a) Flange thickness $(\mathrm{m})$,

b) Flange thickness (m) and Web thickness (m), c) Web thickness (m):

i) small case, ii) intermediate case, iii) large case. 
i)
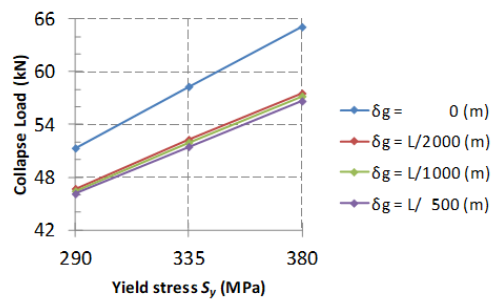

ii)

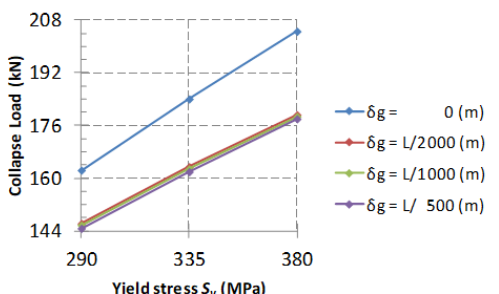

iii)

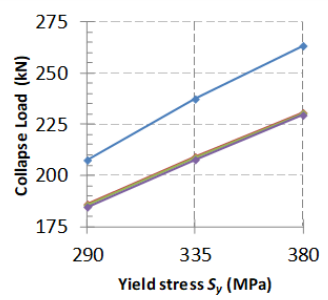

a)

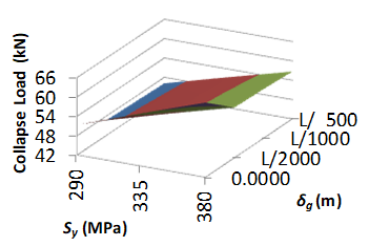

$=42-48=48-54=54-60 \quad=60-66$

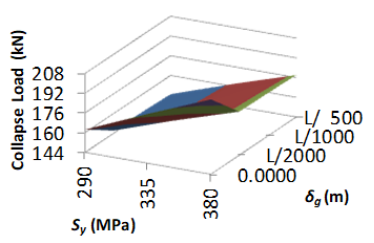

$=144-160=160-176=176-192=192-208$

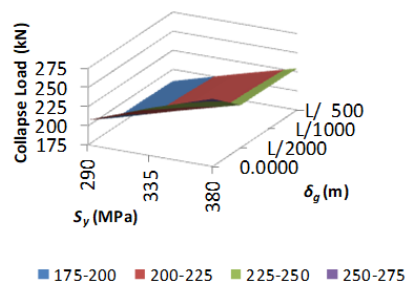

b)
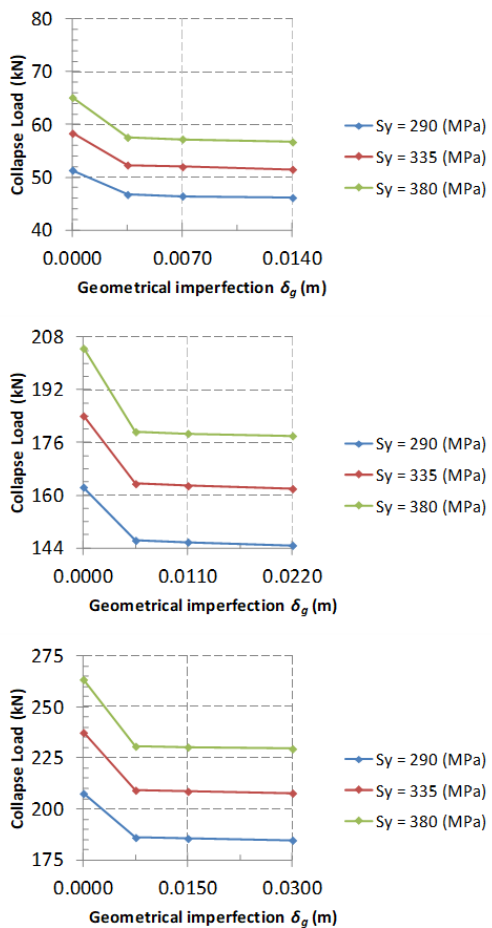

c)

Figure 9 Collapse Load (kN) as a function of the: a) Yield stress (MPa),

b) Yield stress (MPa) and Geometrical imperfection (m), c) Geometrical imperfection (m): i) small case, ii) intermediate case, iii) large case.

It is observed that the results of the Collapse Load as a function of each of the parameters are very similar in the three cases, so from this point on only the intermediate one will be analysed. It is also verified that the variation of the Collapse Load as a function of the parameters Height on a fixed support, Height in the symmetry plane, Flange width, Flange thickness, Web thickness and Yield stress presents a behavior very close to linear. Except for the case in which the Geometric imperfection is zero, the behavior of the Collapse Load can also be considered very close to linear and therefore this case will be disregarded in the next analyses. When analysing the behavior as a function of the Angle, it appears that in the vast majority of the cases the Collapse Load passes through a maximum point for the Angle equal to 17.5 degrees. Among the several possible ones, it was decided to use the quadratic function to approximate the obtained results, and obviously, a negative coefficient for the quadratic term must be used. The Collapse Load behavior as a function of the Length is typically exponential and this function will be used to approximate the results.

To better understand the influence of each of the parameters, approximation functions are determined to estimate the Collapse Load as a function of each pair of parameters, which can assume each of the values shown in Table 1, with the others parameters remaining constant with the values presented in the intermediate case of Table 2 . Initially, this analysis was done without the use of crossed terms in the approximation function. Subsequently, for the cases in which the initial results were not adequate, approximations using crossed terms and even interpolation on all available points were used.

\subsubsection{Approximation function without crossed terms}

\subsubsection{Linear / linear approximation}

Figures 10 to 30 show all cases in which the behavior of the Collapse Load as a function of all pairs of parameters is approximated by a linear function. Each of the figures is organized as follows: part a) presents the Collapse Load as a function of parameter 1 for different values of parameter 2, part b) presents the same results by inverting parameters 1 and 2, part c) shows a three-dimensional graph of the Collapse Load as a function of the two parameters simultaneously and part d) shows the same three-dimensional graph of the obtained approximation function. 


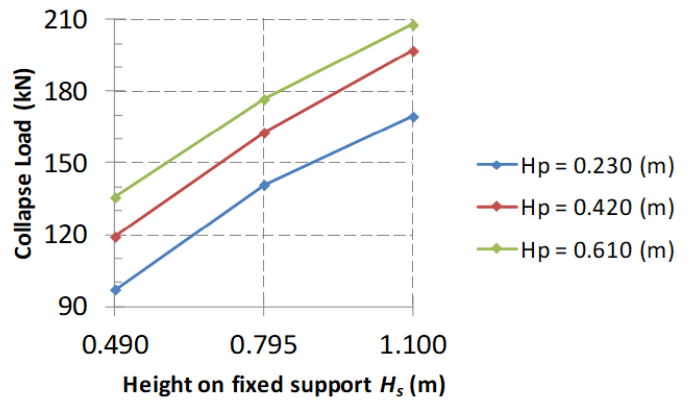

a)

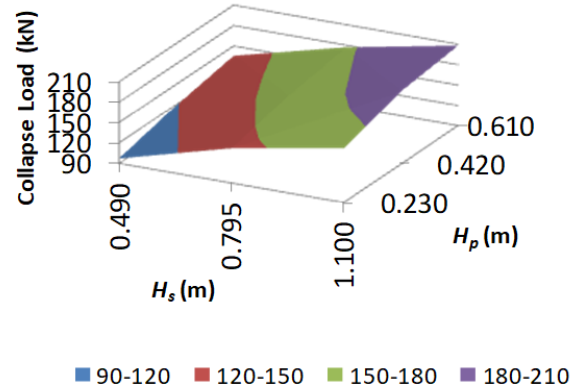

c)

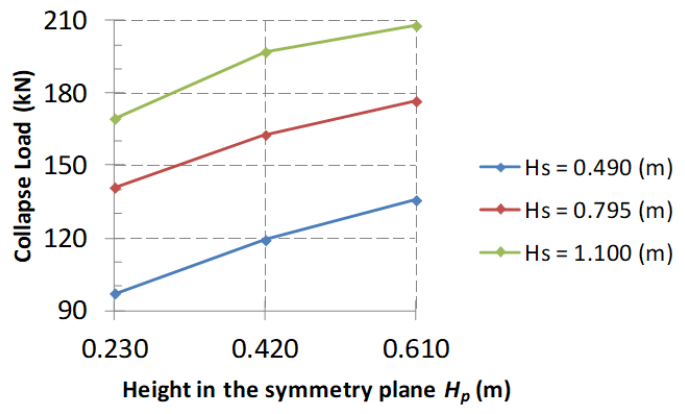

b)

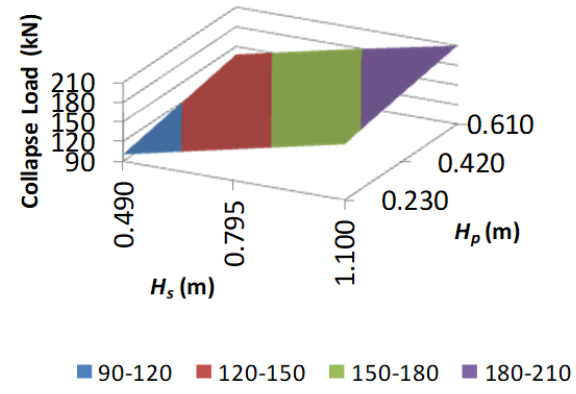

d)

Figure 10 Collapse Load $(\mathrm{kN})$ as a function of the: a) Height on fixed support $(\mathrm{m})$, b) Height in the symmetry plane $(\mathrm{m})$, c) Height on fixed support $(\mathrm{m})$ and Height in the symmetry plane $(\mathrm{m})$, d) linear/linear approximation.

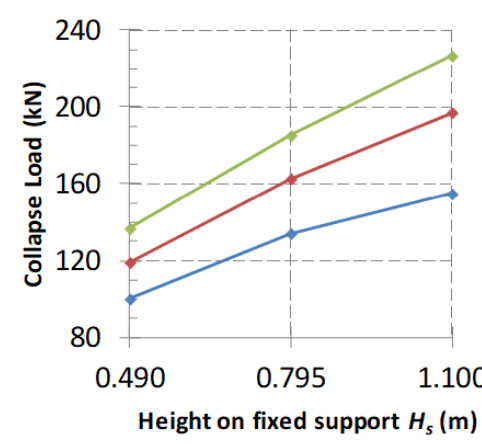

a)

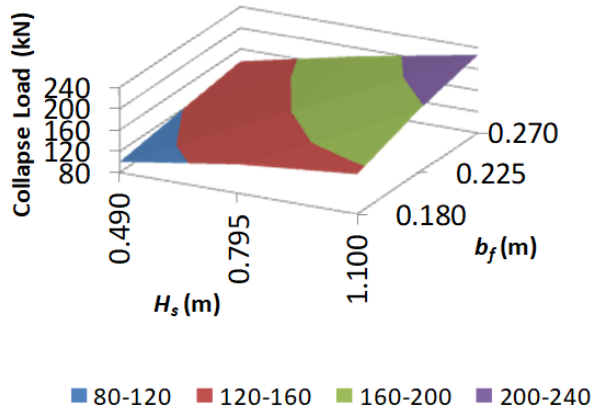

c)

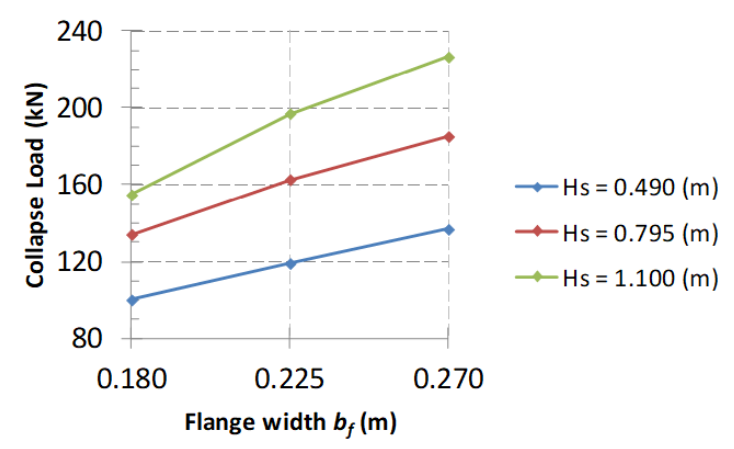

b)

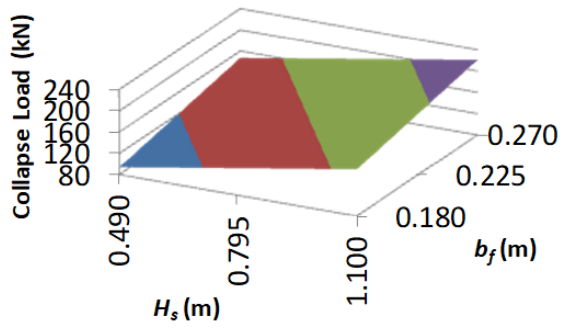

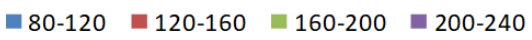

d)

Figure 11 Collapse Load ( $k N)$ as a function of the: a) Height on fixed support (m), b) Flange width (m), c) Height on fixed support $(\mathrm{m})$ and Flange width $(\mathrm{m})$, d) linear/linear approximation. 


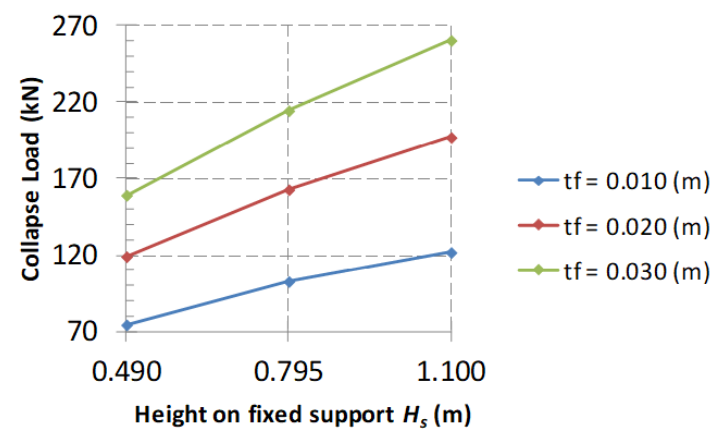

a)

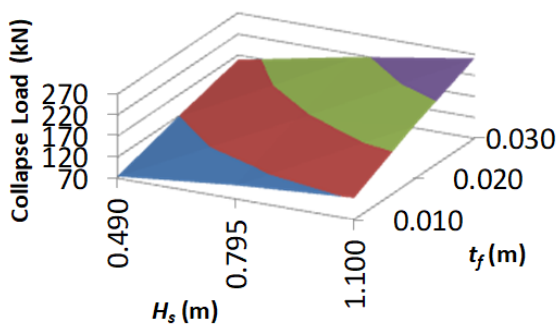

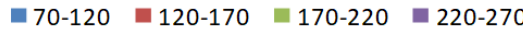

c)

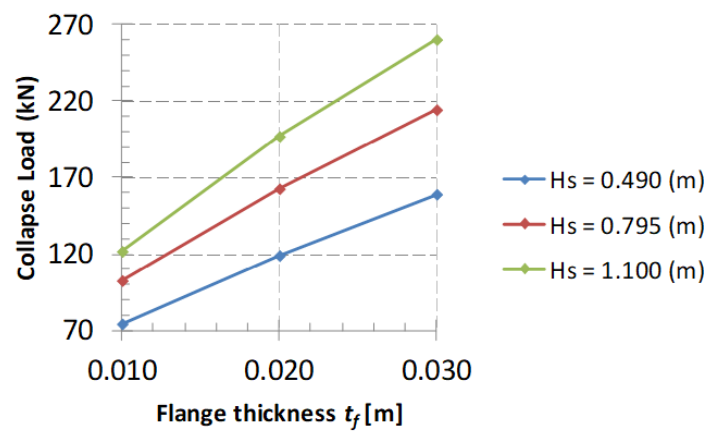

b)

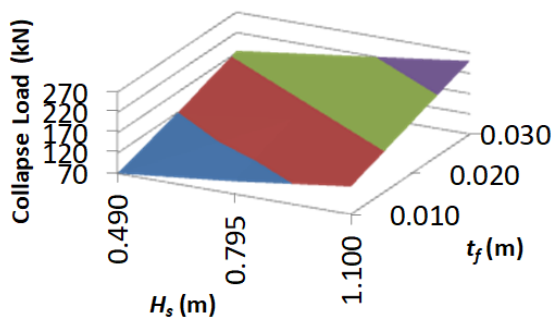

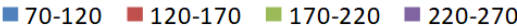

d)

Figure 12 Collapse Load $(\mathrm{kN})$ as a function of the: a) Height on fixed support $(\mathrm{m})$, b) Flange thickness $(\mathrm{m})$, c) Height on fixed support $(m)$ and Flange thickness $(m)$, d) linear/linear approximation.

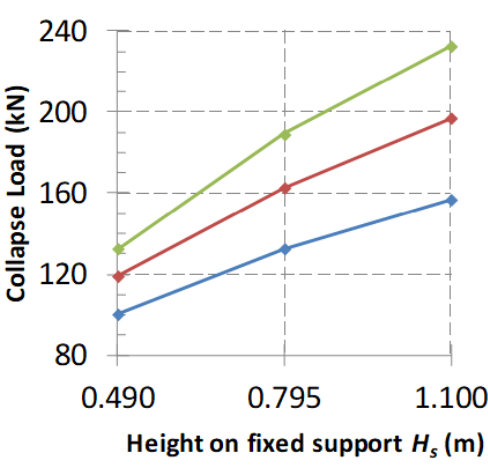

a)

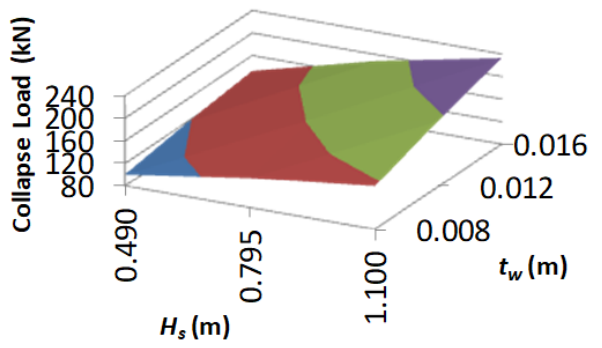

- 80-120 $=120-160=160-200 \quad$ 200-240

c)

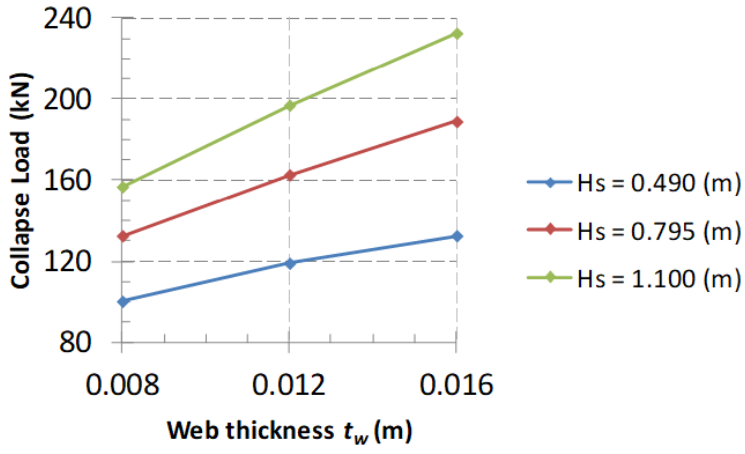

b)

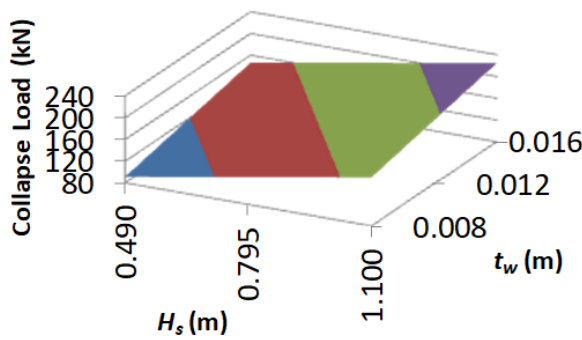

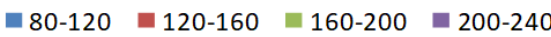

d)

Figure 13 Collapse Load (kN) as a function of the: a) Height on fixed support (m), b) Web thickness (m),

c) Height on fixed support $(m)$ and Web thickness $(m)$, d) linear/linear approximation. 


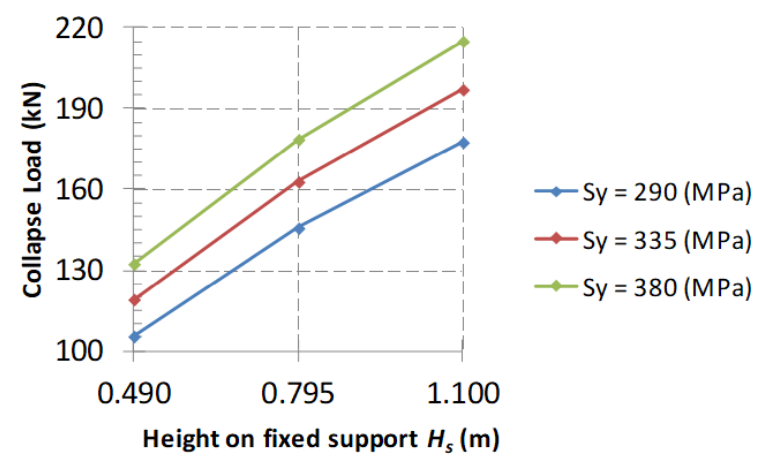

a)

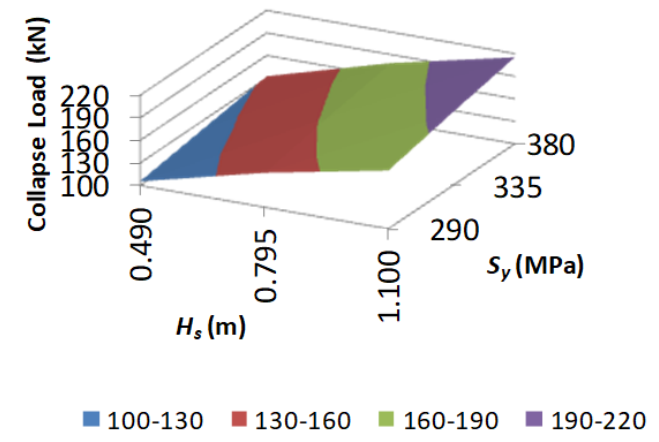

c)

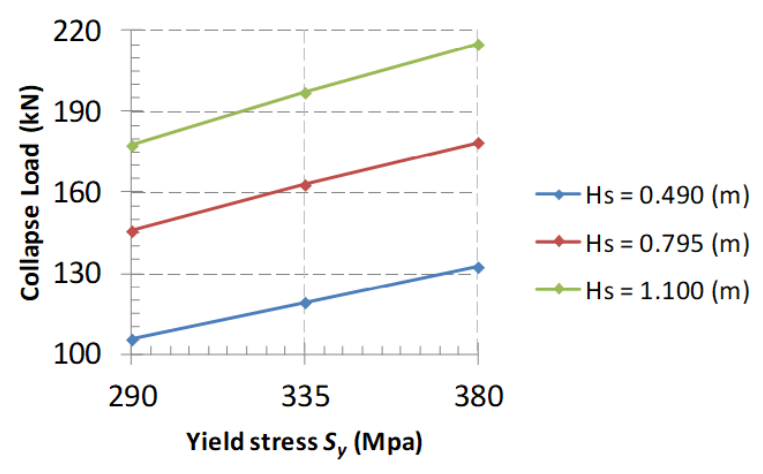

b)

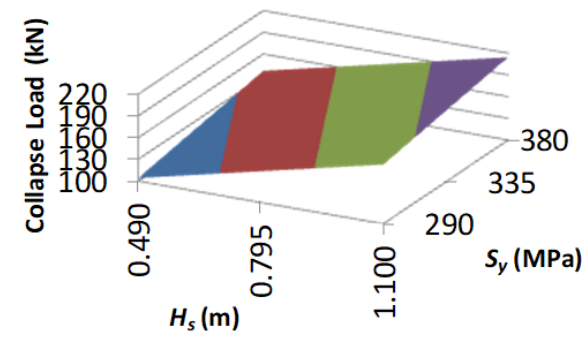

$\square 100-130 \quad 130-160=160-190 \quad \square 190-220$

d)

Figure 14 Collapse Load (kN) as a function of the: a) Height on fixed support (m), b) Yield stress (MPa),

c) Height on fixed support $(\mathrm{m})$ and Yield stress (MPa), d) linear/linear approximation.

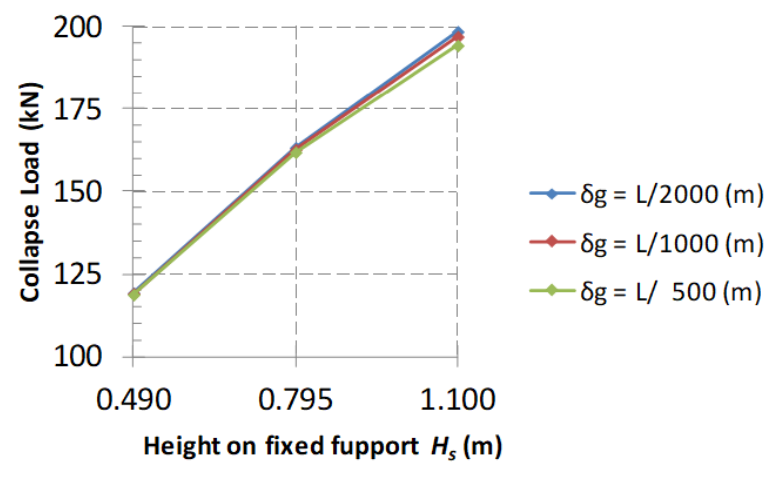

a)

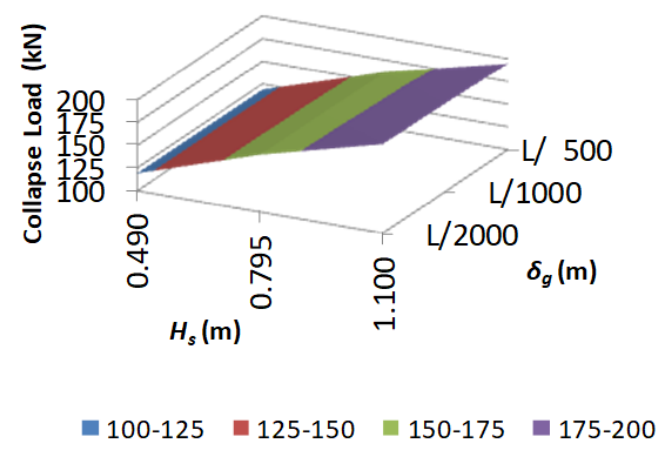

c)

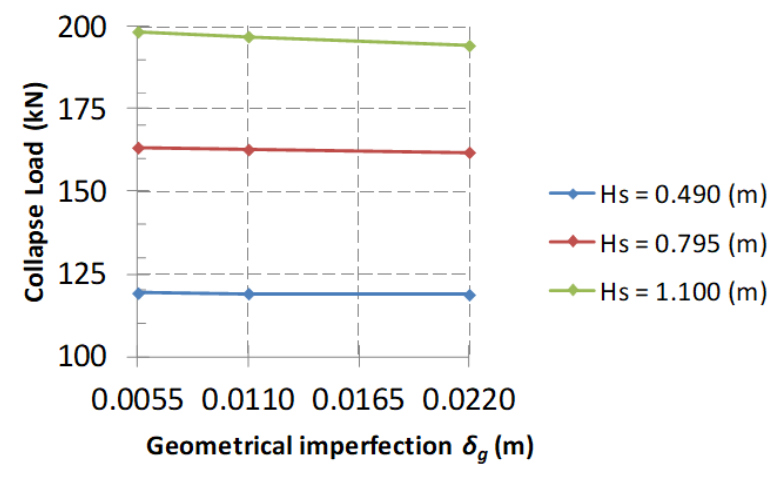

b)

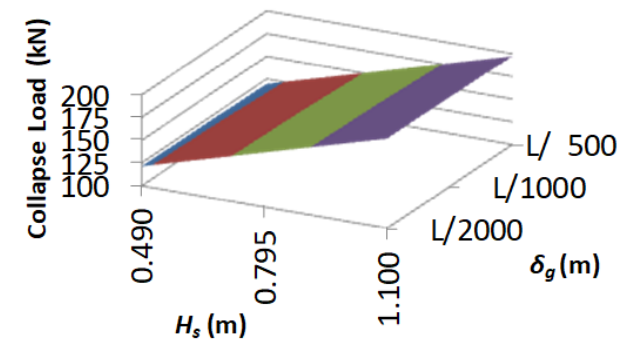

- $100-125 \quad \square 125-150 \quad \square 150-175=175-200$

d)

Figure 15 Collapse Load (kN) as a function of the: a) Height on fixed support (m), b) Geometric imperfection (m),

c) Height on fixed support $(m)$ and Geometric imperfection $(m)$, d) linear/linear approximation. 


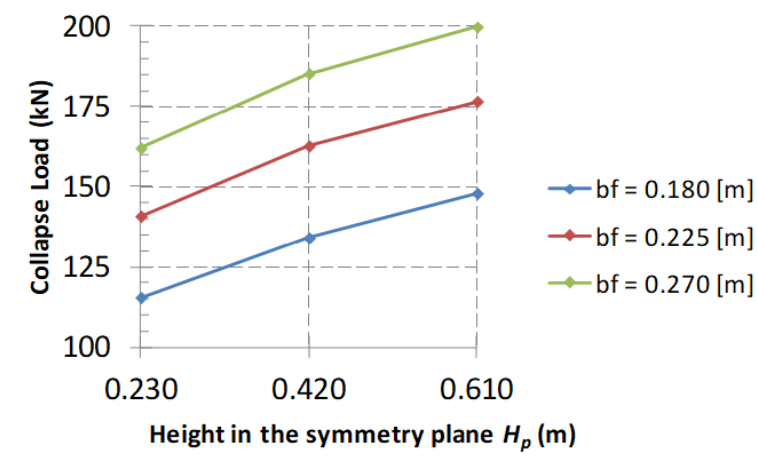

a)

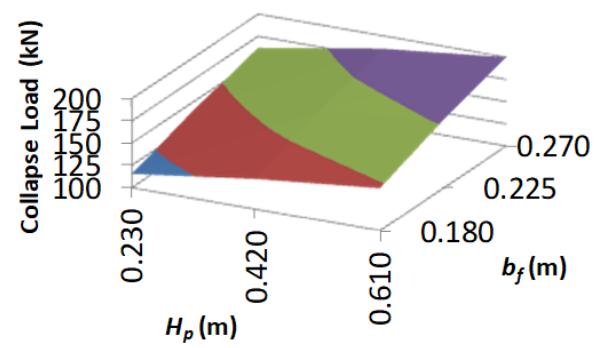

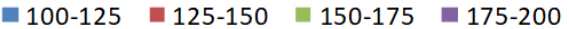

c)

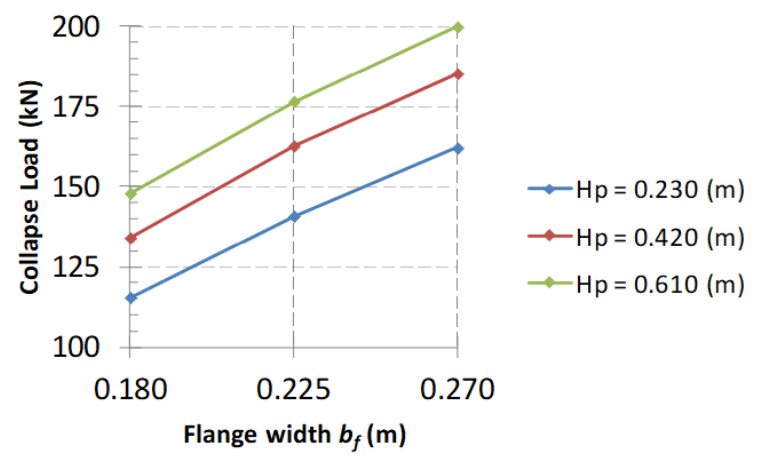

b)

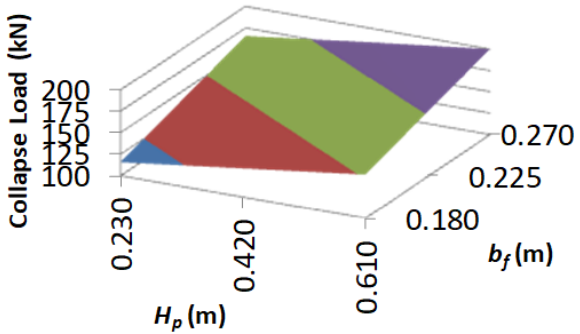

a $100-125$ - 125-150 $150-175=175-200$

d)

Figure 16 Collapse Load $(\mathrm{kN})$ as a function of the: a) Height in the symmetry plane $(\mathrm{m}), \mathrm{b})$ Flange width $(\mathrm{m})$, c) Height in the symmetry plane $(\mathrm{m})$ and Flange width $(\mathrm{m}), \mathrm{d})$ linear/linear approximation.

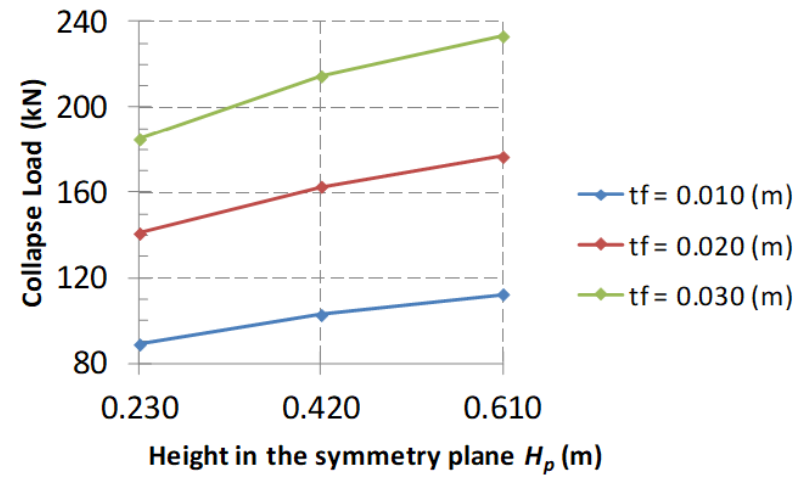

a)

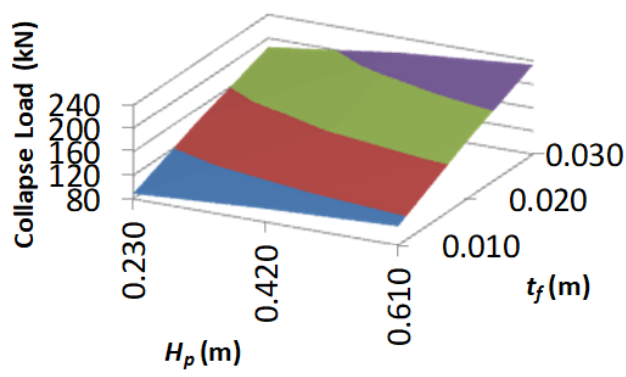

$\square$ - 80-120 $\quad 120-160 \square 160-200 \square 200-240$

c)

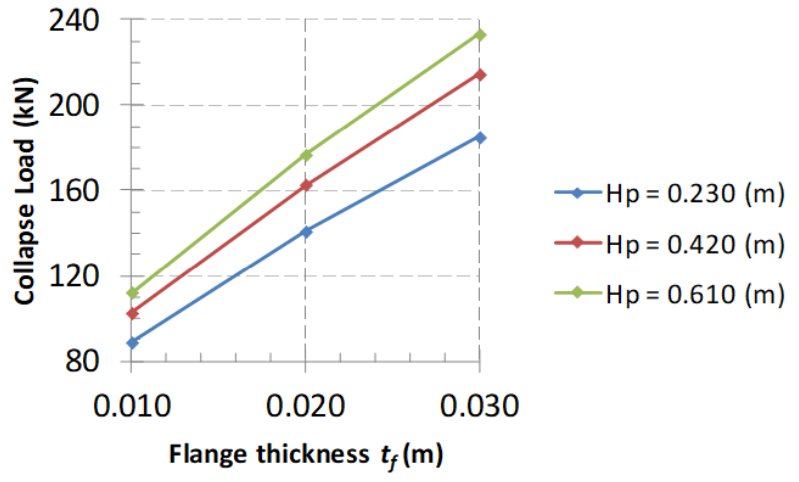

b)

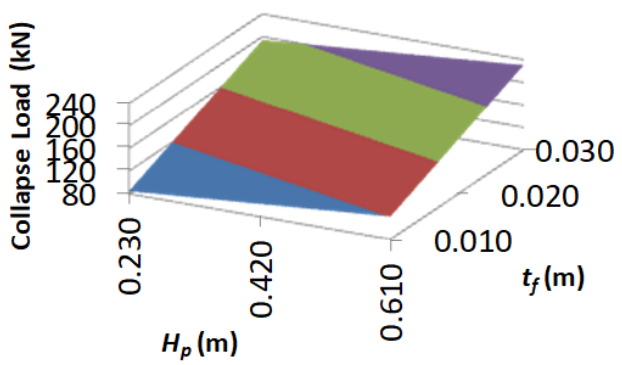

$\square=80-120 \quad 120-160 \quad 160-200 \quad$ a 200-240

d)

Figure 17 Collapse Load (kN) as a function of the: a) Height in the symmetry plane (m), b) Flange thickness $(\mathrm{m})$, c) Height in the symmetry plane $(\mathrm{m})$ and Flange thickness $(\mathrm{m})$, d) linear/linear approximation. 


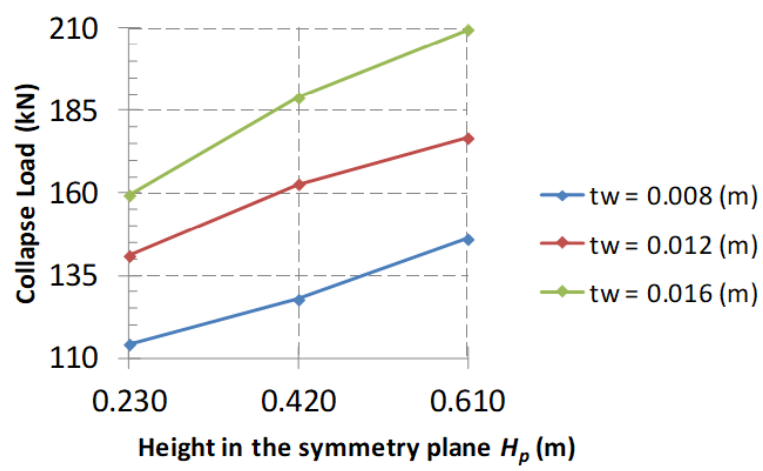

a)

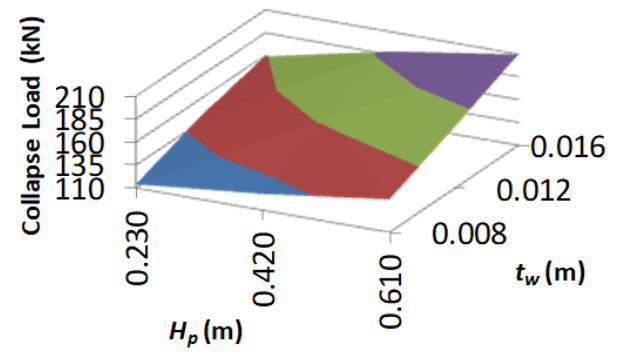

$\square$ 110-135 $=135-160=160-185=185-210$

c)

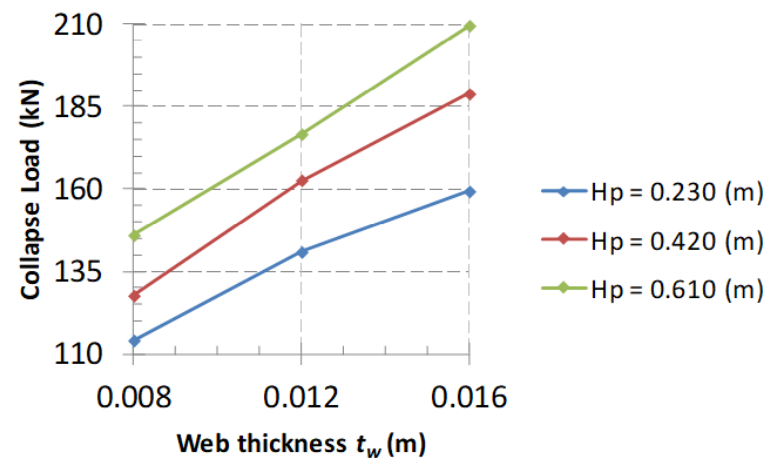

b)

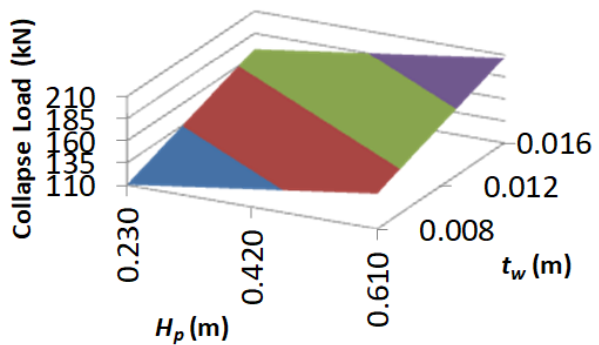

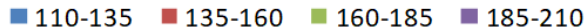

d)

Figure 18 Collapse Load $(\mathrm{kN})$ as a function of the: a) Height in the symmetry plane $(\mathrm{m}), \mathrm{b})$ Web thickness $(\mathrm{m})$, c) Height in the symmetry plane $(m)$ and Web thickness $(m), d)$ linear/linear approximation.

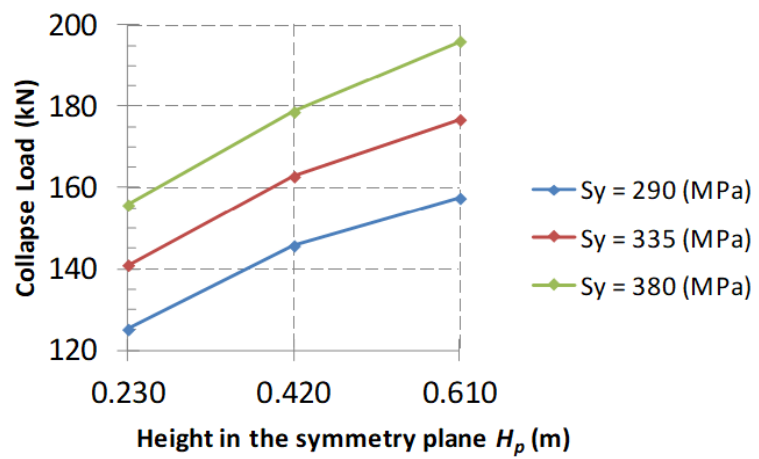

a)

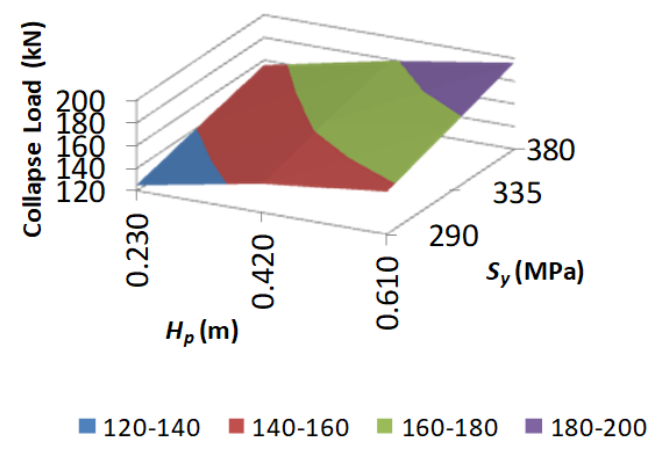

c)

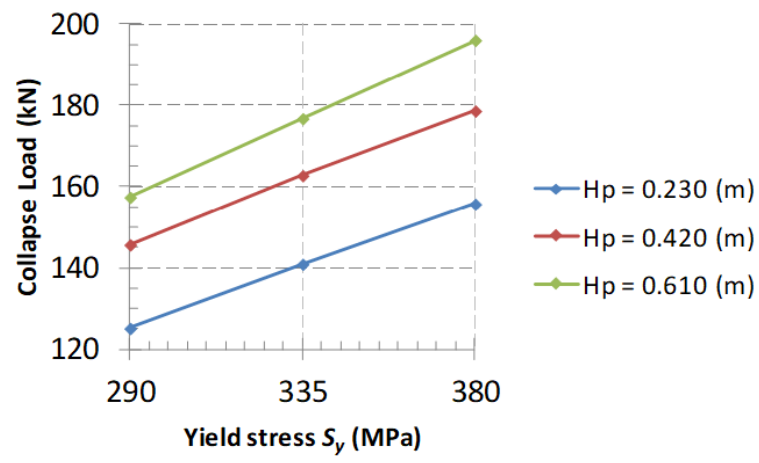

b)

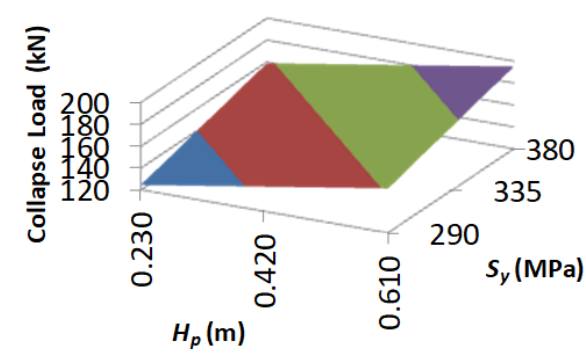

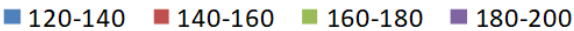

d)

Figure 19 Collapse Load (kN) as a function of the: a) Height in the symmetry plane (m), b) Yield stress (MPa),

c) Height in the symmetry plane $(\mathrm{m})$ and Yield stress (MPa), d) linear/linear approximation. 


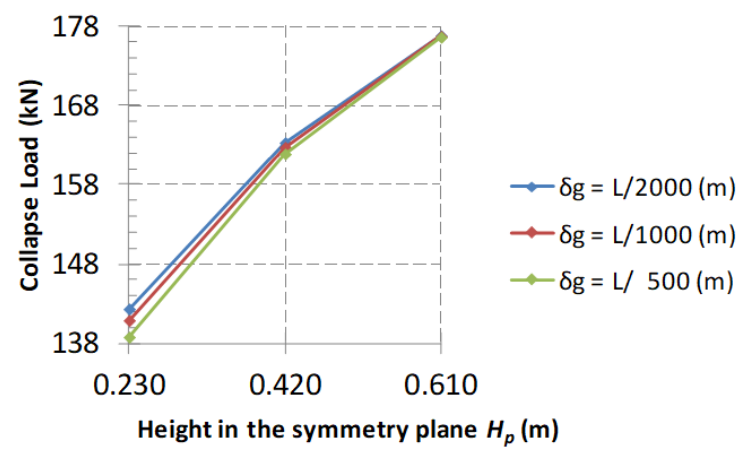

a)

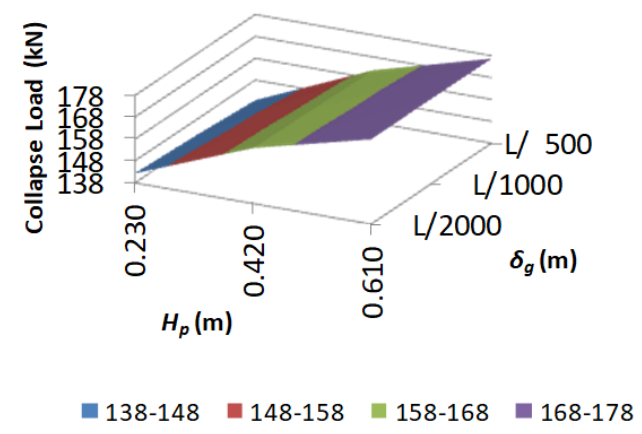

c)

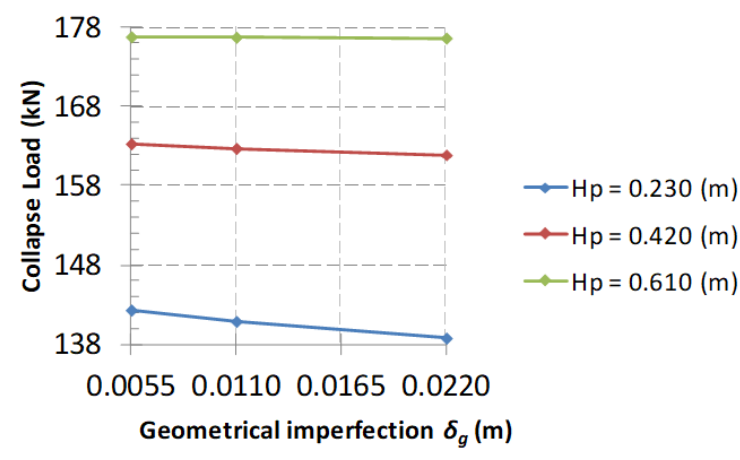

b)

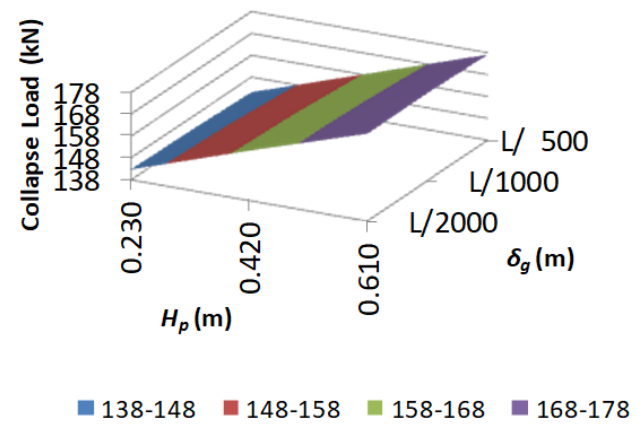

d)

Figure 20 Collapse Load $(\mathrm{kN})$ as a function of the: a) Height in the symmetry plane $(\mathrm{m}), \mathrm{b})$ Geometrical imperfection (m), c) Height in the symmetry plane $(\mathrm{m})$ and Geometrical imperfection $(\mathrm{m})$, d) linear/linear approximation.

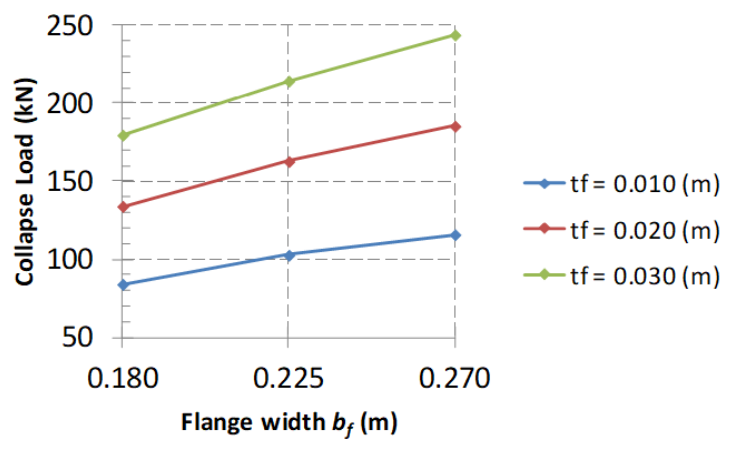

a)

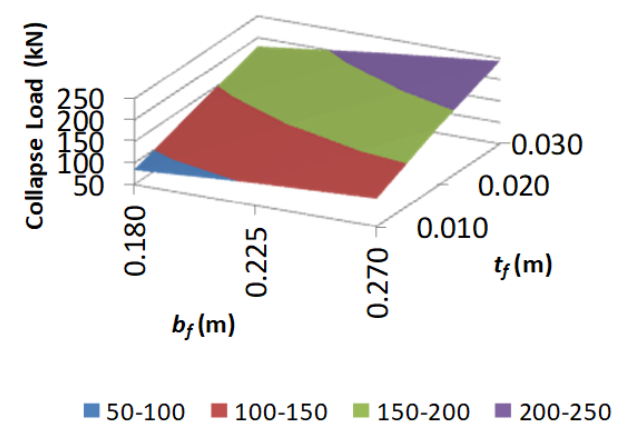

c)

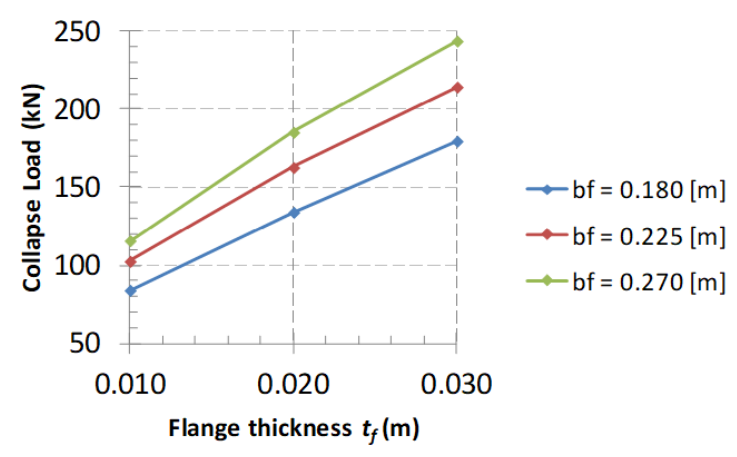

b)

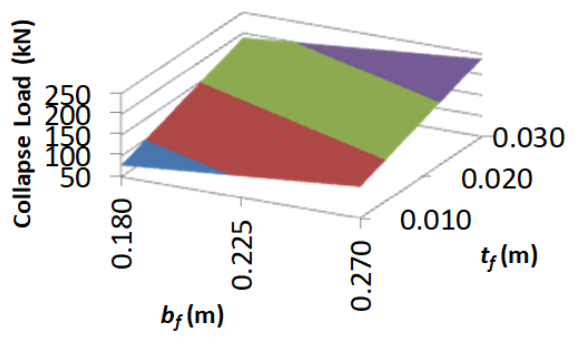

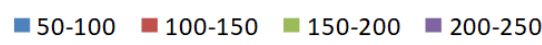

d)

Figure 21 Collapse Load $(\mathrm{kN})$ as a function of the: a) Flange width $(\mathrm{m})$, b) Flange thickness $(\mathrm{m})$,

c) Flange width $(m)$ and Flange thickness $(m)$, d) linear/linear approximation. 


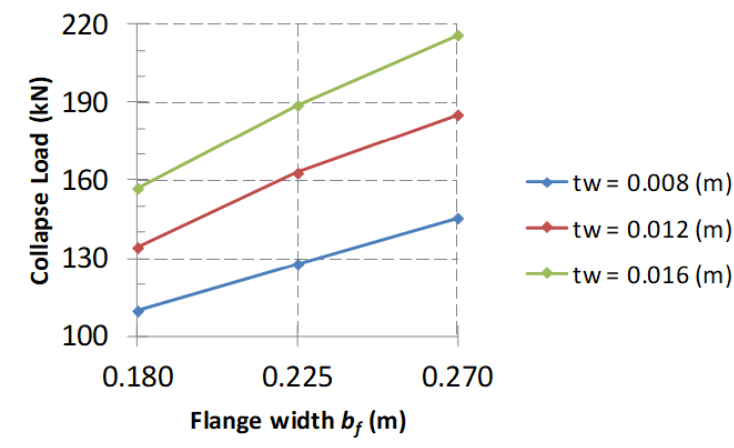

a)

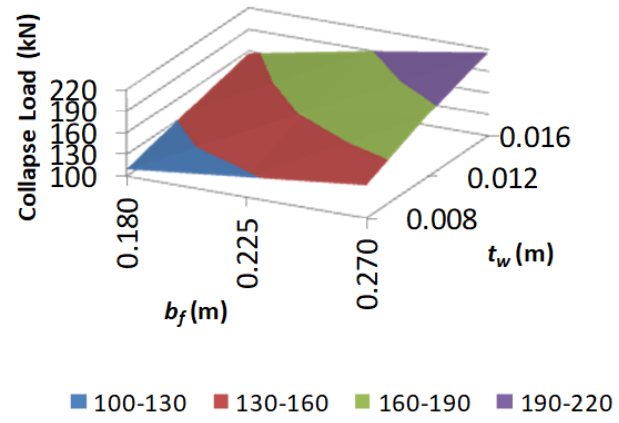

c)

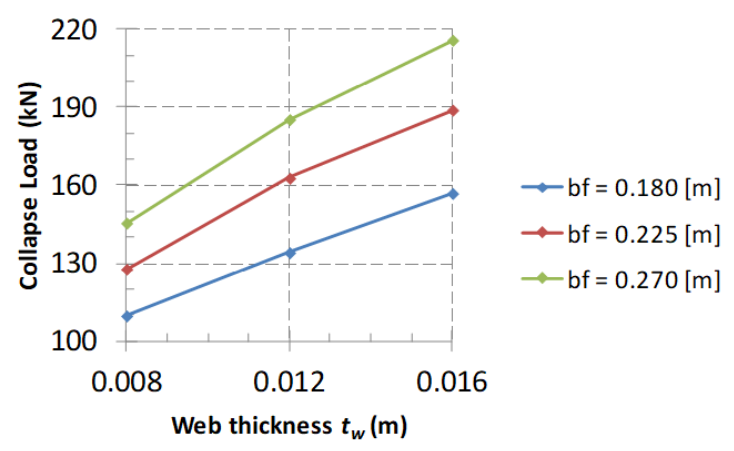

b)

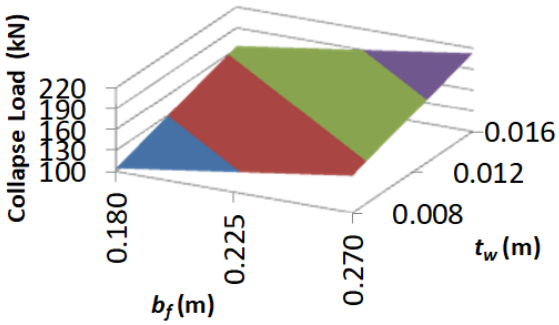

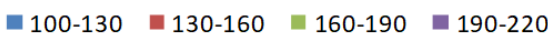

d)

Figure 22 Collapse Load (kN) as a function of the: a) Flange width (m), b) Web thickness (m),

c) Flange width $(\mathrm{m})$ and Web thickness $(\mathrm{m})$, d) linear/linear approximation.

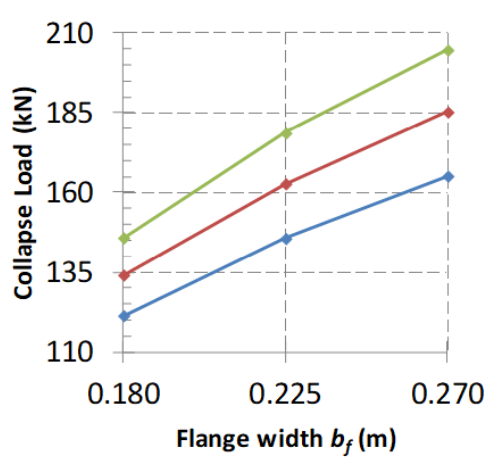

a)

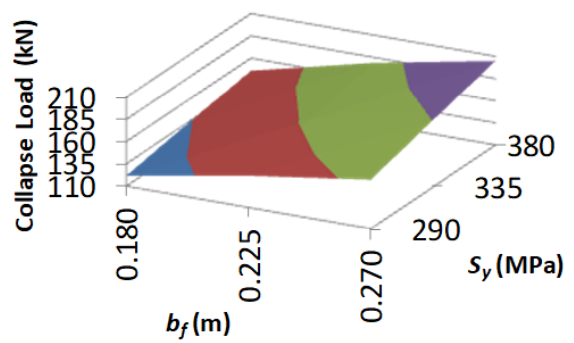

- 110-135 = 135-160 - 160-185-210

c)

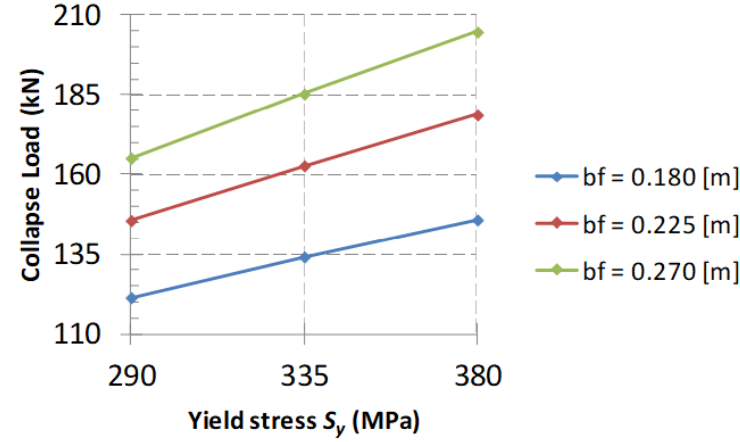

b)

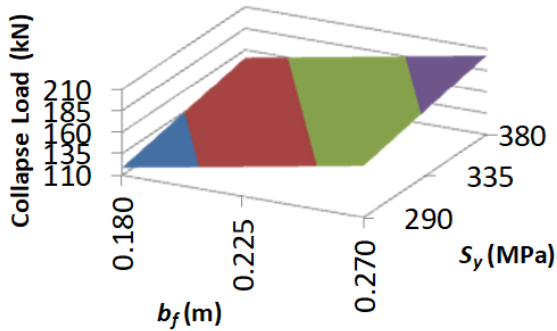

$\square 110-135-135-160=160-185=185-210$

d)

Figure 23 Collapse Load $(\mathrm{kN})$ as a function of the: a) Flange width $(\mathrm{m})$, b) Yield stress (MPa),

c) Flange width $(\mathrm{m})$ and Yield stress (MPa), d) linear/linear approximation. 


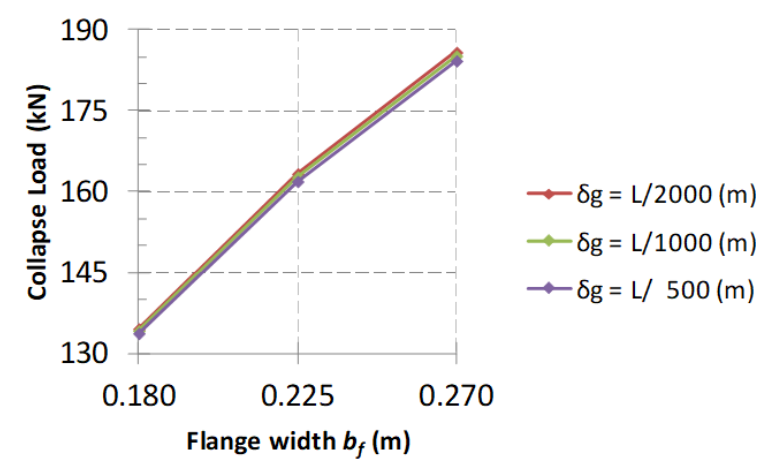

a)

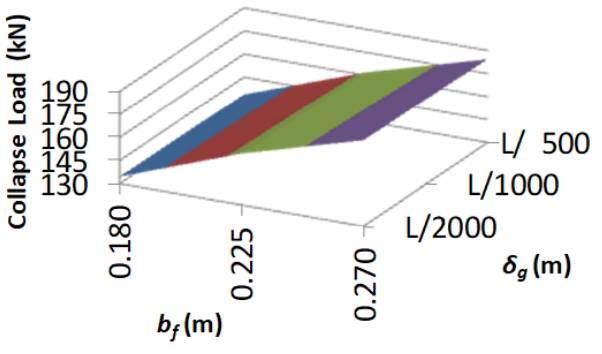

-130-145 - =145-160 - 160-175-190

c)

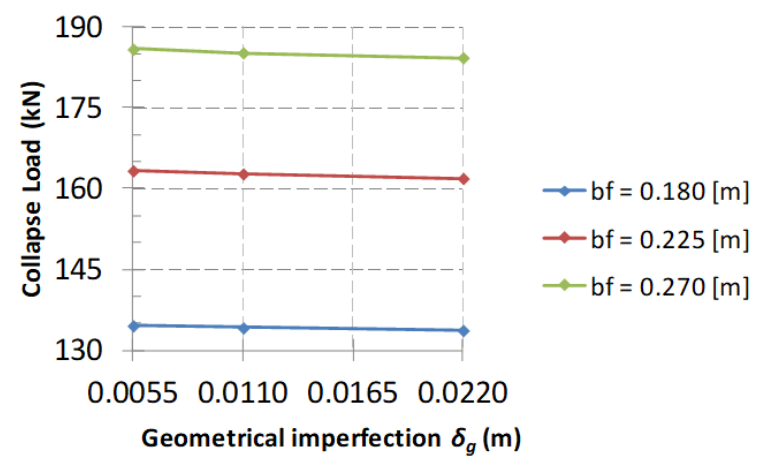

b)

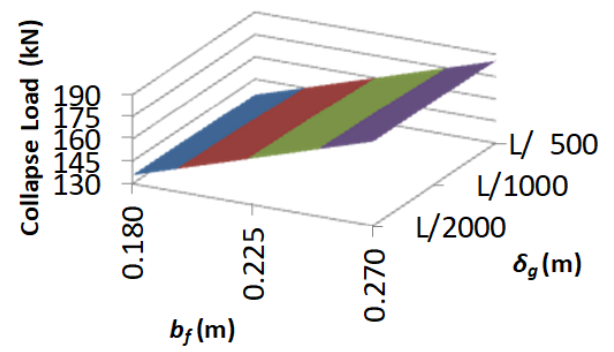

-130-145 -145-160 $=160-175=175-190$

d)

Figure 24 Collapse Load $(\mathrm{kN})$ as a function of the: a) Flange width $(\mathrm{m})$, b) Geometrical imperfection $(\mathrm{m})$, c) Flange width $(m)$ and Geometrical imperfection $(m)$, d) linear/linear approximation.

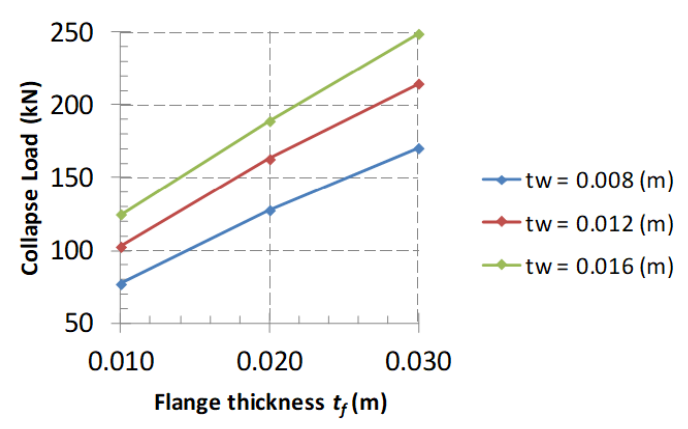

a)

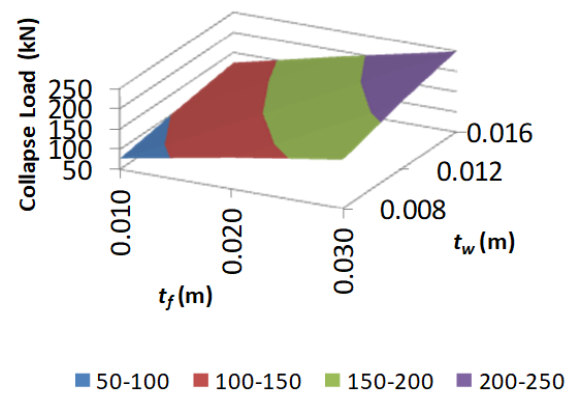

c)

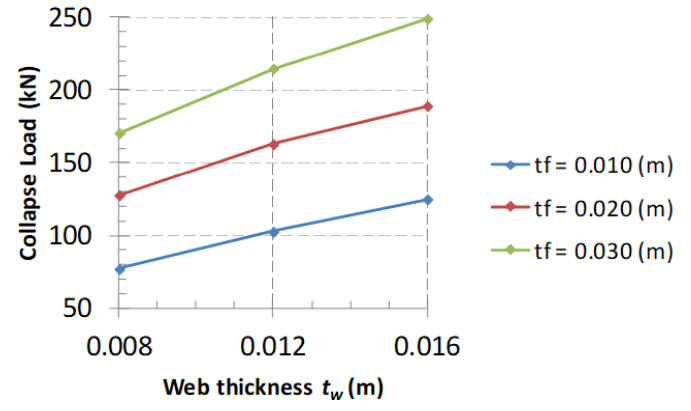

b)

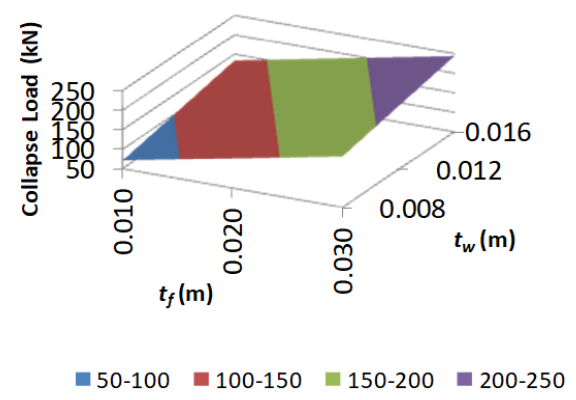

d)

Figure 25 Collapse Load $(\mathrm{kN})$ as a function of the: a) Flange thickness $(\mathrm{m}), \mathrm{b})$ Web thickness $(\mathrm{m})$,

c) Flange thickness $(m)$ and Web thickness $(m)$, d) linear/linear approximation. 


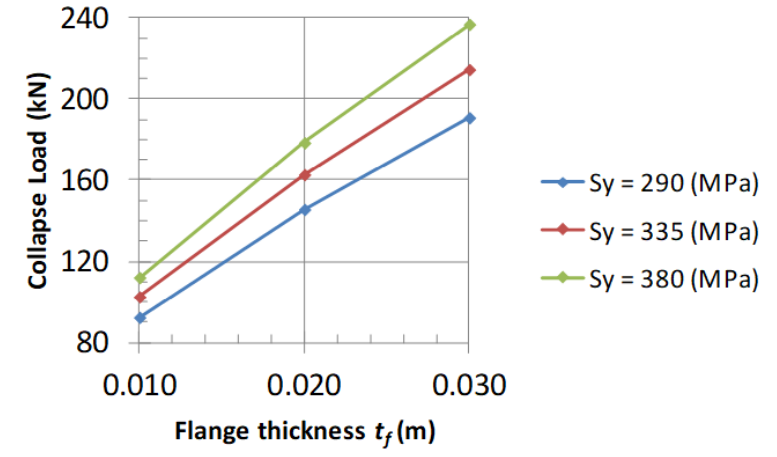

a)

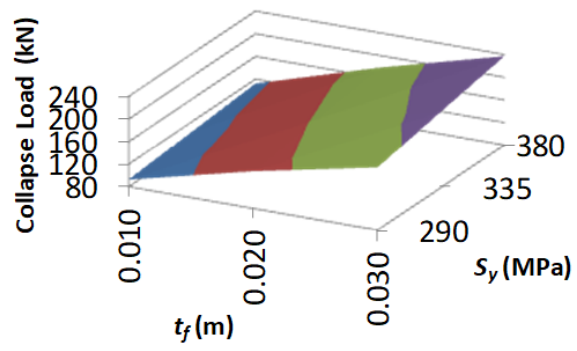

= 80-120 $=120-160=160-200 \quad \square 200-240$

c)

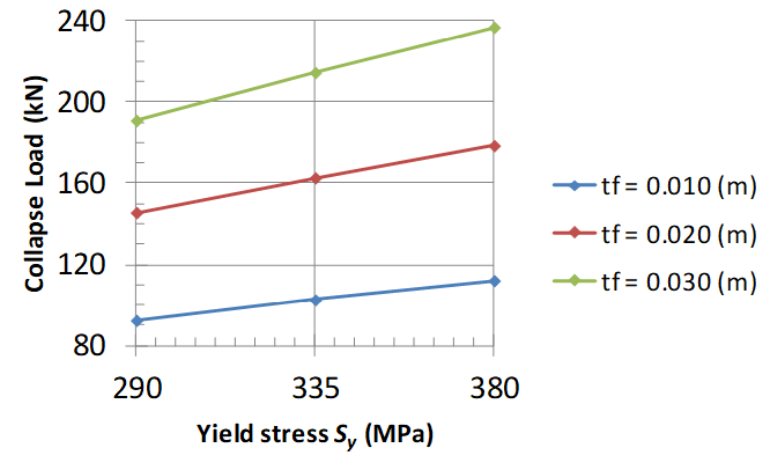

b)

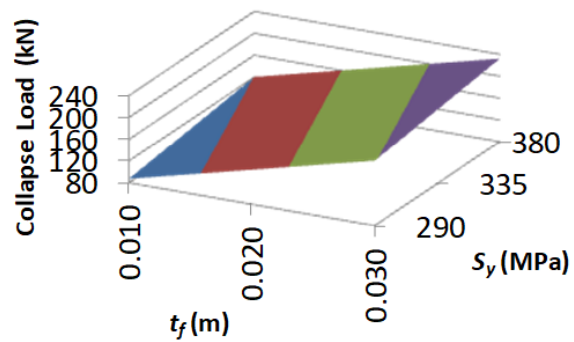

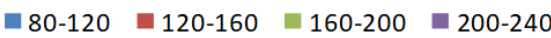

d)

Figure 26 Collapse Load $(\mathrm{kN})$ as a function of the: a) Flange thickness (m), b) Yield stress (MPa) (m), c) Flange thickness $(\mathrm{m})$ and Yield stress (MPa), d) linear/linear approximation.

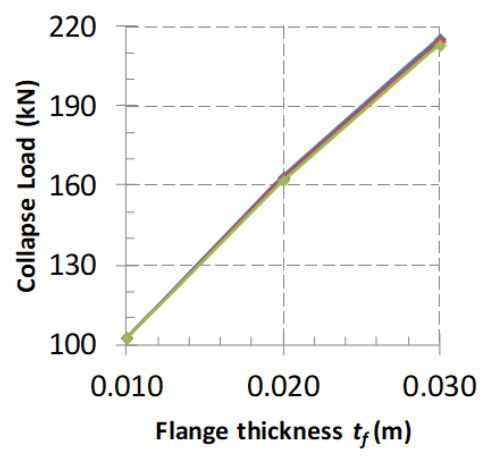

a)

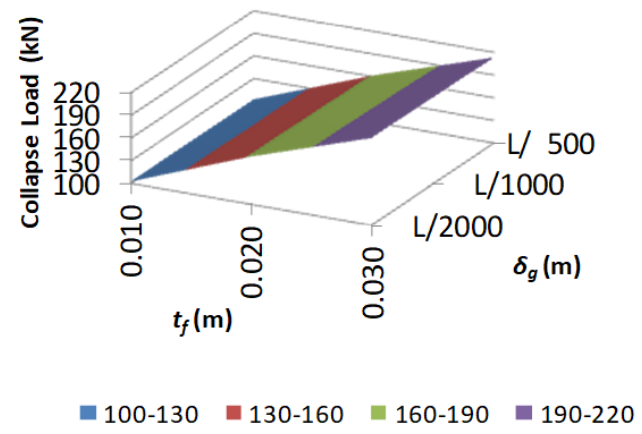

c)

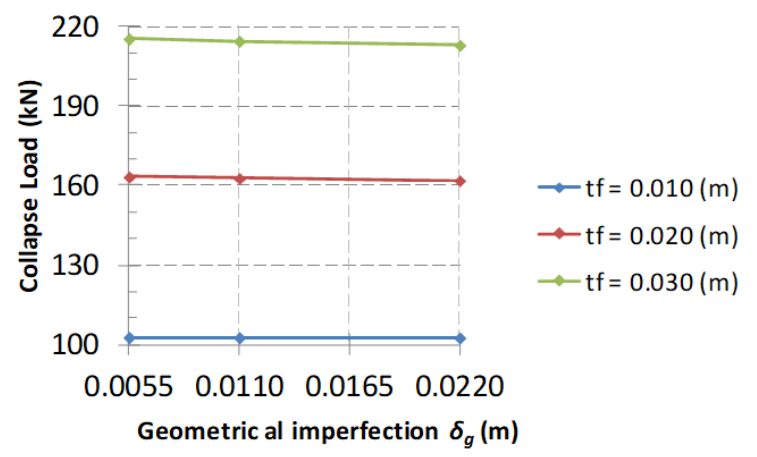

b)

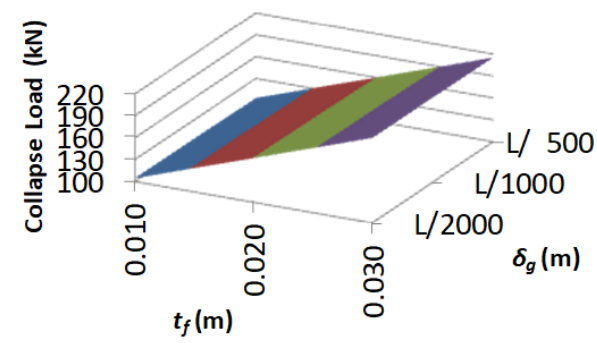

-100-130 =130-160 $=160-190=190-220$

d)

Figure 27 Collapse Load (kN) as a function of the: a) Flange thickness $(\mathrm{m})$, b) Geometrical imperfection $(\mathrm{m})$, c) Flange thickness $(\mathrm{m})$ and Geometrical imperfection $(\mathrm{m})$, d) linear/linear approximation. 


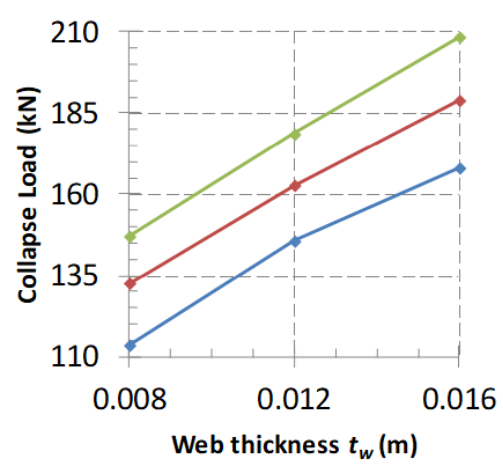

a)

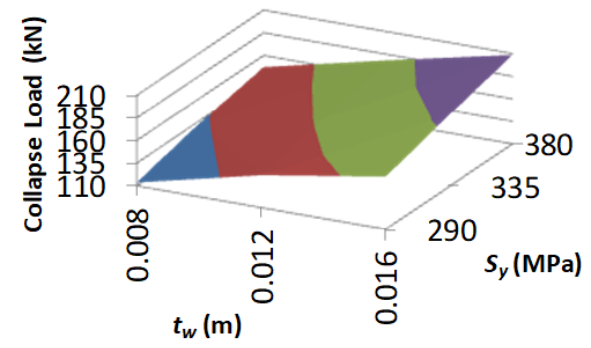

-110-135 -135-160 -160-185 $185-210$

c)

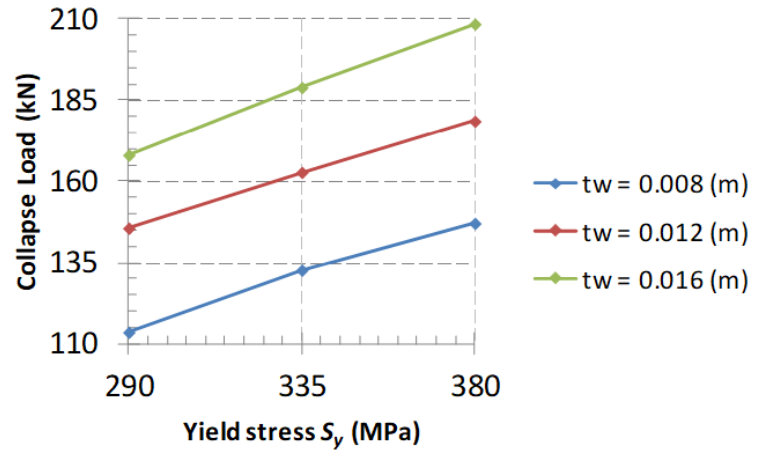

b)

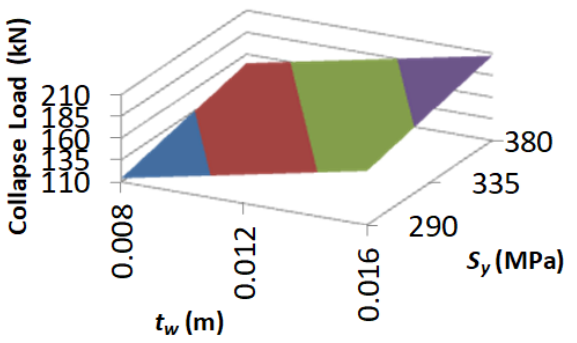

-110-135 -135-160 -160-185 $=185-210$

d)

Figure 28 Collapse Load (kN) as a function of the: a) Web thickness (m), b) Yield stress (MPa), c) Web thickness $(\mathrm{m})$ and Yield stress (MPa), d) linear/linear approximation.

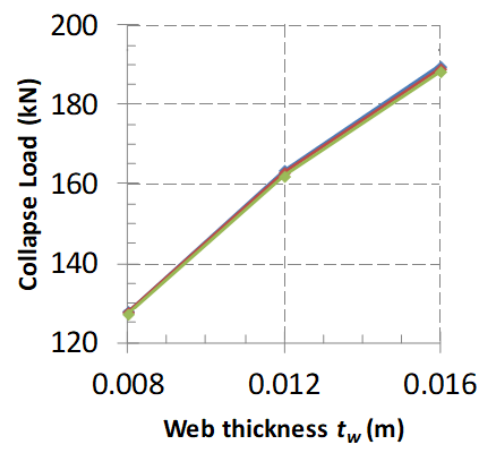

a)

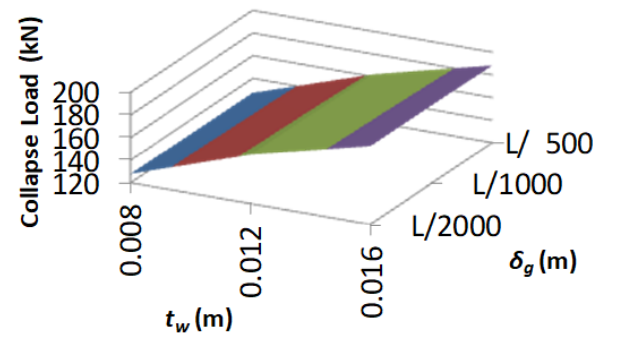

= $120-140=140-160=160-180 \quad$ = $180-200$

c)

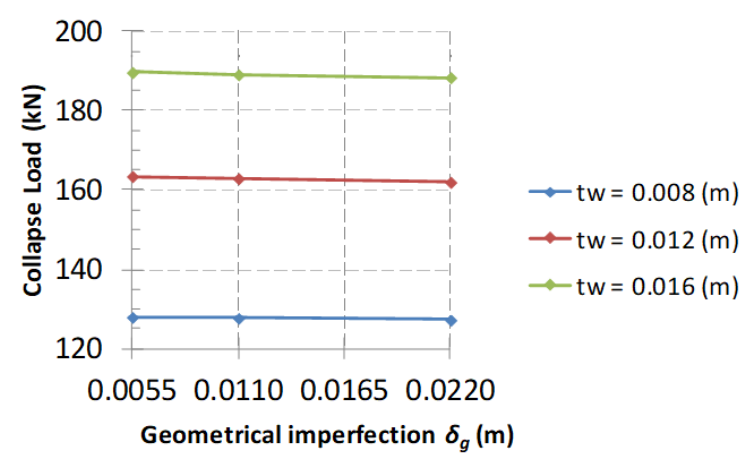

b)

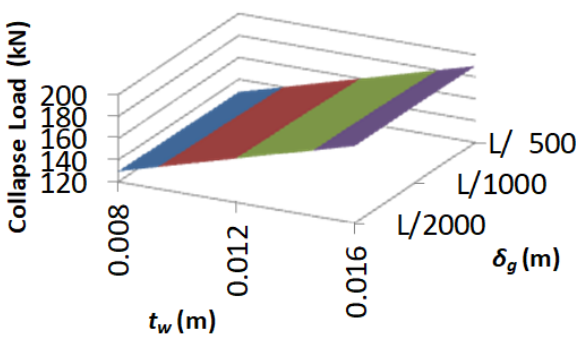

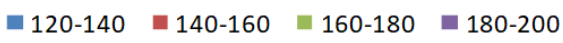

d)

Figure 29 Collapse Load $(\mathrm{kN})$ as a function of the: a) Web thickness (m), b) Geometrical imperfection (m),

c) Web thickness $(m)$ and Geometrical imperfection $(m)$, d) linear/linear approximation. 


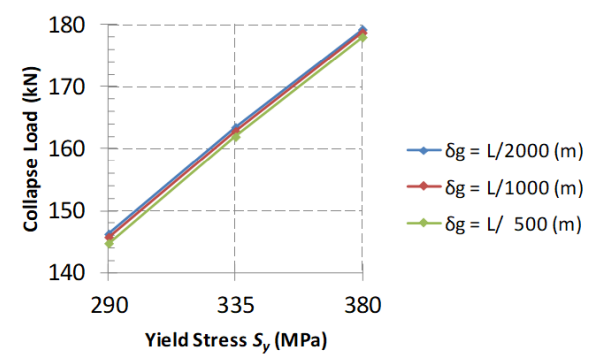

a)

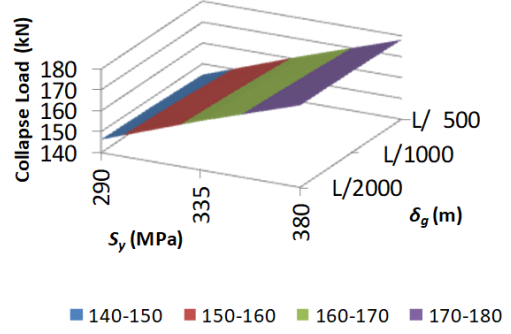

c)

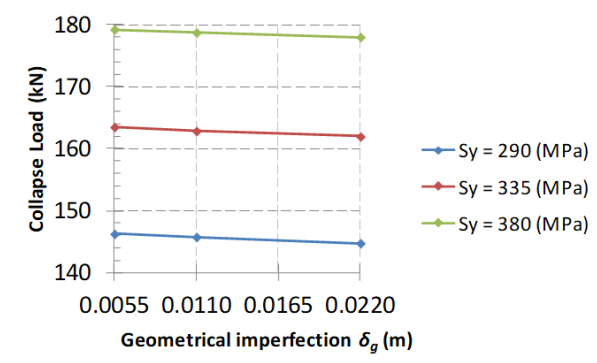

b)

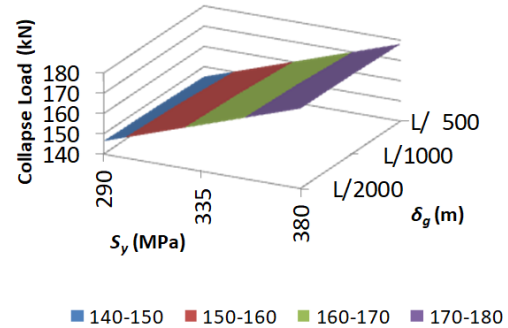

d)

Figure 30 Collapse Load (kN) as a function of the: a) Yield stress (MPa), b) Geometrical imperfection (m),

c) Yield stress (MPa) and Geometrical imperfection $(\mathrm{m})$, d) linear/linear approximation.

For each pair of parameters analysed, Table 3 presents the figure in which the results of the analysis are shown, the approximation function and the error range in which the differences between the results obtained in the FEA and the approximation functions are found. Negative values indicate that the result obtained in the approximation function is less than that in the FEA. In this and the other analysis that will be presented, the null Geometrical imperfection was suppressed in determining the approximation function. Except for two cases, all error modules between the approximation function and the FEA are below $10 \%$. This result is a first indication that the choice of linear functions for the analysis of the influence of these parameters may be adequate.

Table 3 Linear / linear approximation function.

\begin{tabular}{|c|c|c|c|}
\hline Parameters & Figure & Approximation Function & Error Range \\
\hline$H_{s} \times H_{p}$ & $10 d$ & $17.9850+121.7235 \times H_{s}+98.9381 \times H_{p}$ & $-3.97 \%$ to $3.43 \%$ \\
\hline$H_{s} \times b_{f}$ & $11 d$ & $-72.0582+121.5051 \times H_{s}+590.5014 \times b_{f}$ & $-8.46 \%$ to $6.38 \%$ \\
\hline$H_{s} \times t_{f}$ & $12 d$ & $-53.4217+123.8998 \times H_{s}+5589.5876 \times t_{f}$ & $-13.89 \%$ to $14.98 \%$ \\
\hline$H_{s} \times t_{w}$ & $13 d$ & $-25.9347+128.1617 \times H_{s}+6847.7297 \times t_{w}$ & $-10.39 \%$ to $8.69 \%$ \\
\hline$H_{s} \times S_{y}$ & $14 d$ & $-62.7264+127.2146 \times H_{s}+0.3608 \times S_{y}$ & $-3.31 \%$ to $2.14 \%$ \\
\hline$H_{s} \times \delta_{g}$ & $15 d$ & $58.8991+127.2186 \times H_{s}-122.2884 \times \delta_{g}$ & $-1.91 \%$ to $2.21 \%$ \\
\hline$H_{p} \times b_{f}$ & $16 d$ & $-5.4330+93.1264 \times H_{p}+554.2283 \times b_{f}$ & $-2.18 \%$ to $2.69 \%$ \\
\hline$H_{p} \times t_{f}$ & $17 d$ & $8.0969+94.3507 \times H_{p}+5485.5708 \times t_{f}$ & $-7.35 \%$ to $4.70 \%$ \\
\hline$H_{p} \times t_{w}$ & $18 d$ & $29.9246+103.4737 \times H_{p}+7091.4315 \times t_{w}$ & $-4.88 \%$ to $3.22 \%$ \\
\hline$H_{p} \times S_{y}$ & $19 d$ & $-6.8312+95.1199 \times H_{p}+0.3785 \times S_{y}$ & $-2.22 \%$ to $1.92 \%$ \\
\hline$H_{p} \times \delta_{g}$ & $20 d$ & $121.5024+94.8580 \times H_{p}-101.9965 \times \delta_{g}$ & $-1.64 \%$ to $1.75 \%$ \\
\hline$b_{f} \times t_{f}$ & $21 d$ & $-76.4869+545.1089 \times b_{f}+5594.6737 \times t_{f}$ & $-9.41 \%$ to $7.62 \%$ \\
\hline$b_{f} \times t_{w}$ & $22 d$ & $-52.5854+540.7963 \times b_{f}+7454.3996 \times t_{w}$ & $-5.19 \%$ to $4.82 \%$ \\
\hline$b_{f} \times S_{y}$ & $23 d$ & $-88.1212+569.5954 \times b_{f}+0.3594 \times S_{y}$ & $-3.49 \%$ to $2.32 \%$ \\
\hline$b_{f} \times \delta_{g}$ & $24 d$ & $34.1984+566.3630 \times b_{f}-76.5365 \times \delta_{g}$ & $-0.87 \%$ to $1.32 \%$ \\
\hline$t_{f} \times t_{w}$ & $25 d$ & $-46.1103+5493.3751 \times t_{f}+7819.0364 \times t_{w}$ & $-7.24 \%$ to $7.41 \%$ \\
\hline$t_{f} \times S_{y}$ & $26 d$ & $-74.6151+5588.2153 \times t_{f}+0.3657 \times S_{y}$ & $-7.16 \%$ to $5.55 \%$ \\
\hline$t_{f} \times \delta_{g}$ & $27 d$ & $49.1193+5589.0297 \times t_{f}-78.6824 \times \delta_{g}$ & $-7.16 \%$ to $5.55 \%$ \\
\hline$t_{w} \times S_{y}$ & $28 d$ & $-58.1174+7178.9590 \times t_{w}+0.3959 \times S_{y}$ & $-2.05 \%$ to $1.93 \%$ \\
\hline$t_{w} \times \delta_{g}$ & $29 d$ & $68.5953+7672.0109 \times t_{w}-69.8072 \times \delta_{g}$ & $-1.31 \%$ to $1.92 \%$ \\
\hline$S_{y} \times \delta_{g}$ & $30 d$ & $40.3416+0.3674 \times S_{y}-84.6634 \times \delta_{g}$ & $-0.18 \%$ to $0.31 \%$ \\
\hline
\end{tabular}




\subsubsection{Approximation quadratic/linear}

Figures 31 to 37 show all cases in which the behavior of the Collapse Load is approximated by a quadratic function of the Angle and a linear function of the other parameter. Each of the figures is organized as follows: part a) presents the Collapse Load as a quadratic function of the Angle for different values of the other parameter, part c) presents the behavior as a linear function of the other parameter for different values of the Angle, part b) shows a three-dimensional graph of the Collapse Load as a function of the Angle and the other parameter simultaneously, part d) shows the same three-dimensional graph of the obtained approximation function and part e) shows an interpolation function that will be commented in section 4.2.4.

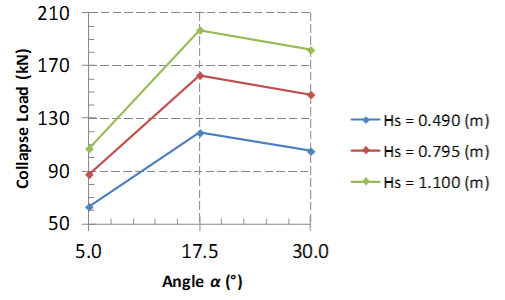

a)

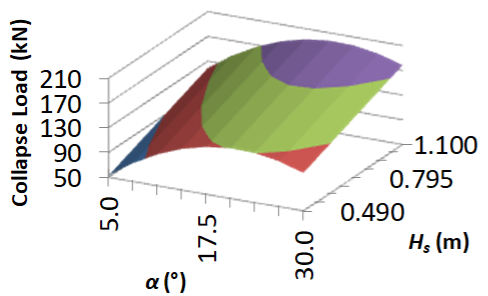

= $50-90 \quad$ = 90-130 $=130-170 \quad=170-210$

d)

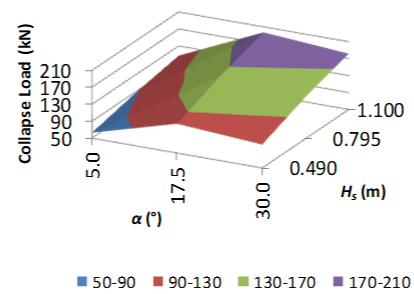

b)

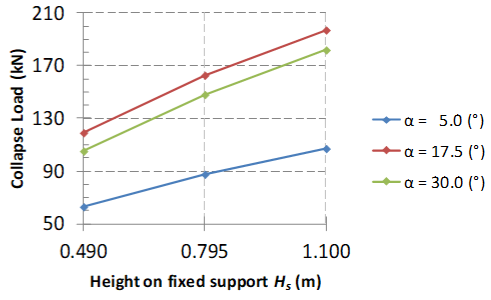

c)

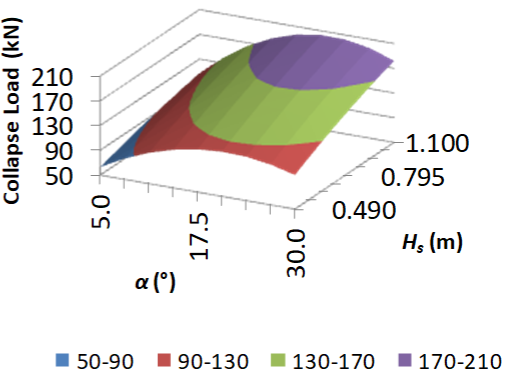

e)

Figure 31 Collapse Load $(\mathrm{kN})$ as a function of the: a) Angle $\left({ }^{\circ}\right)$, b) Angle $\left({ }^{\circ}\right)$ and Height on fixed support $(\mathrm{m})$ c) Height on fixed support (m), d) quadratic/linear approximation, e) polynomial interpolation.

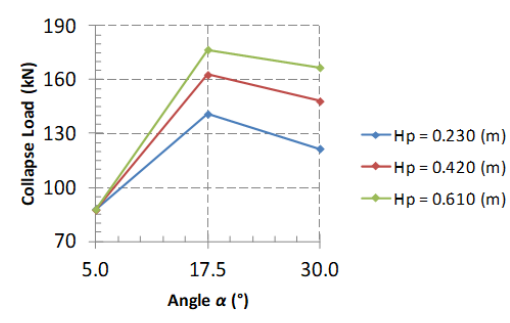

a)

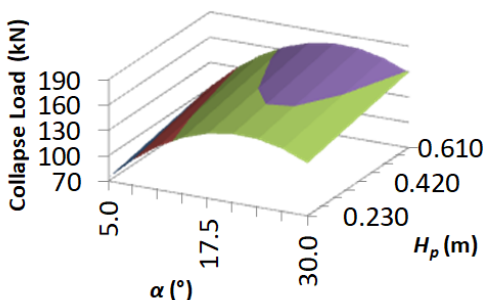

= 70-100 = 100-130 =130-160 =160-190

d)

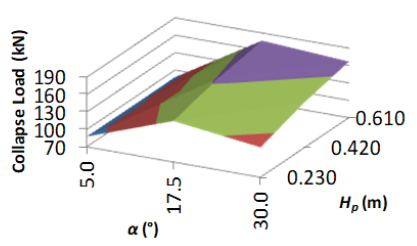

$=70-100=100-130=130-160 \quad=160-190$

b)

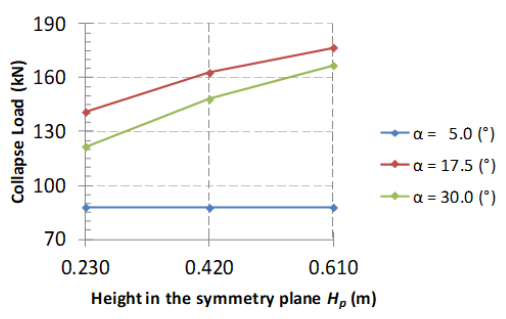

c)

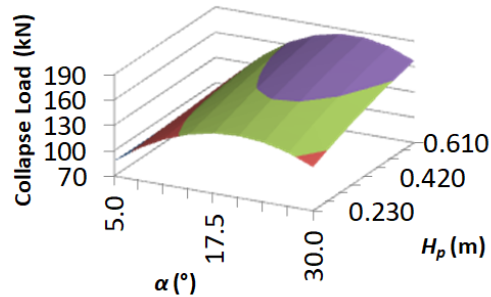

$=70-100 \quad \square 100-130 \quad$ = 130-160 $\quad$ = 160-190

e)

Figure 32 Collapse Load $(\mathrm{kN})$ as a function of the: a) Angle $\left({ }^{\circ}\right)$, b) Angle $\left({ }^{\circ}\right)$ and Height in the symmetry plane $(\mathrm{m})$, c) Height in the symmetry plane $(\mathrm{m})$, d) quadratic/linear approximation, e) polynomial interpolation. 


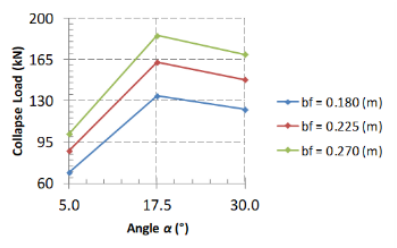

a)

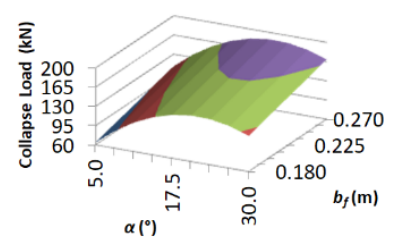

$=60-95=95-130=130-165=165-200$

d)

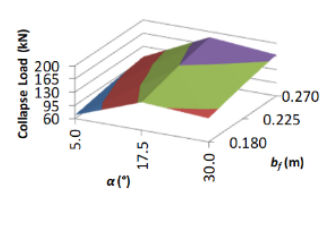

b)

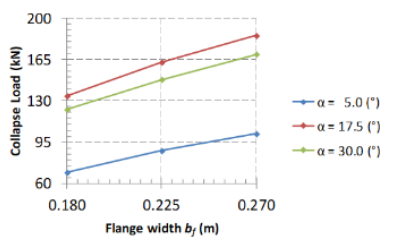

c)

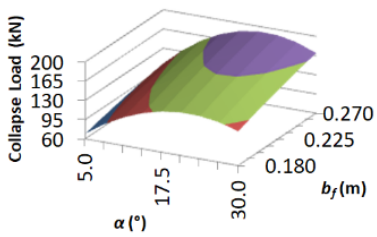

= 60-95 $=95-130=130-165=165-200$

e)

Figure 33 Collapse Load $(\mathrm{kN})$ as a function of the: a) Angle $\left({ }^{\circ}\right)$, b) Angle $\left({ }^{\circ}\right)$ and Flange width $(\mathrm{m})$,

c) Flange width $(\mathrm{m})$, d) quadratic/linear approximation, e) polynomial interpolation.

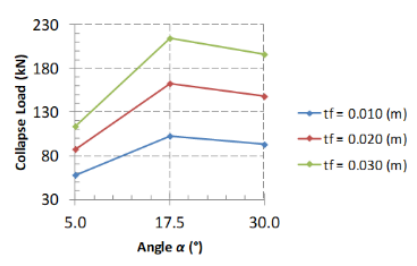

a)

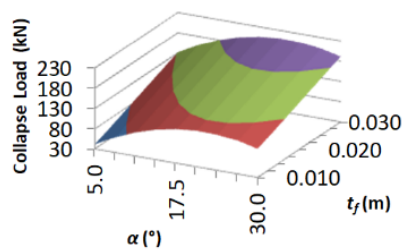

$=30-80=80-130=130-180=180-230$

d)

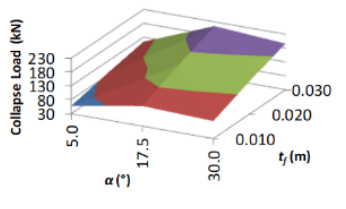

b)

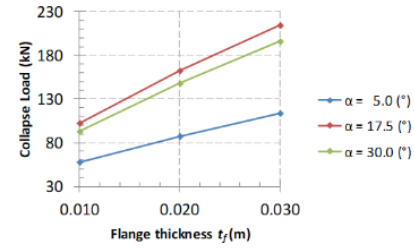

c)

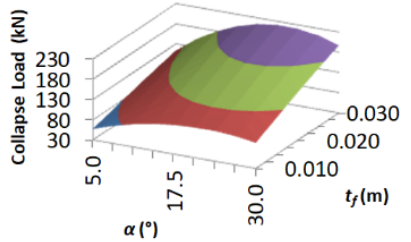

= $30-80=80-130=130-180=180-230$

e)

Figure 34 Collapse Load $(\mathrm{kN})$ as a function of the: a) Angle $\left({ }^{\circ}\right)$, b) Angle $\left({ }^{\circ}\right)$ and Flange thickness $(\mathrm{m})$, c) Flange thickness $(\mathrm{m})$, d) quadratic/linear approximation, e) polynomial interpolation.

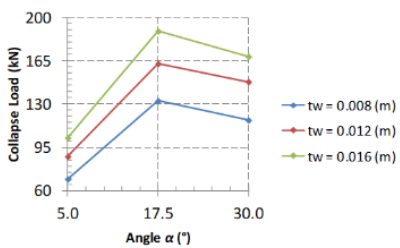

a)

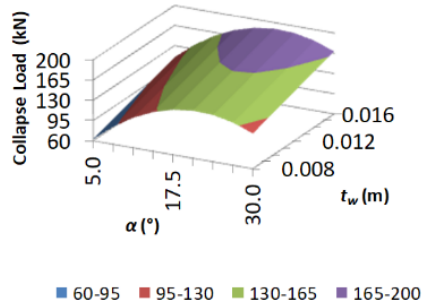

d)

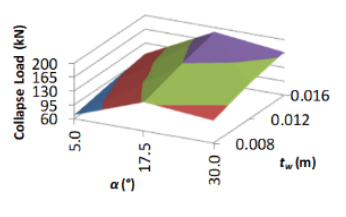

b)

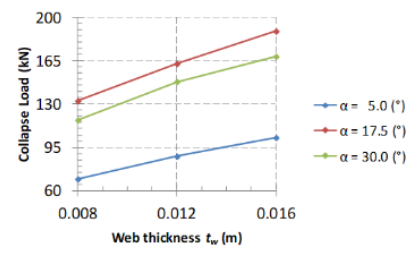

c)

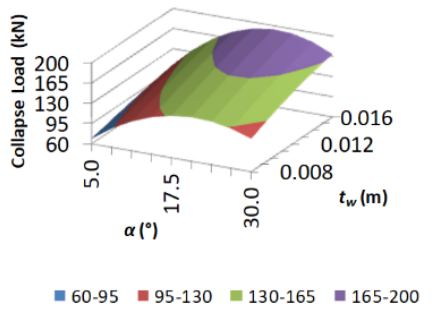

e)

Figure 35 Collapse Load (kN) as a function of the: a) Angle $\left({ }^{\circ}\right)$, b) Angle $\left({ }^{\circ}\right)$ and Web thickness $(\mathrm{m})$, c) Web thickness $(\mathrm{m})$, d) quadratic/linear approximation, e) polynomial interpolation. 


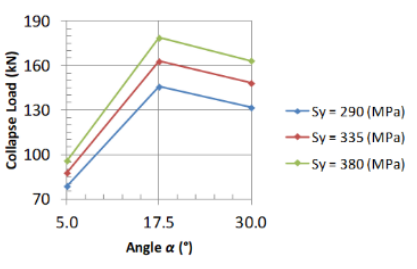

a)

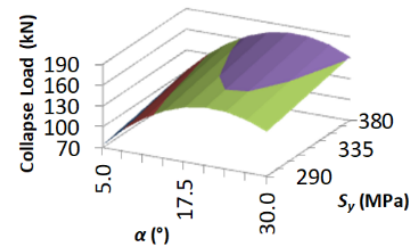

$=70-100=100-130=130-160=160-190$

d)

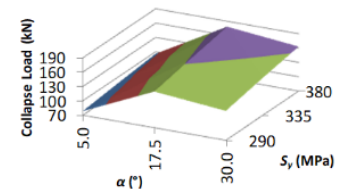

$70-100=100-130=130-160=160-190$

b)

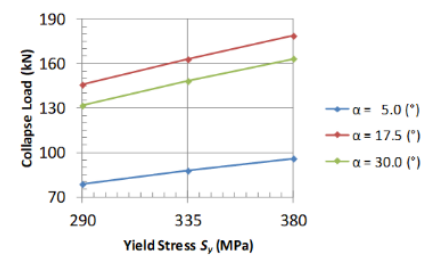

c)

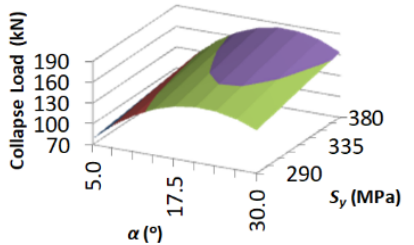

$=70-100=100-130=130-160=160-190$

e)

Figure 36 Collapse Load (kN) as a function of the: a) Angle $\left({ }^{\circ}\right)$, b) Angle $\left({ }^{\circ}\right.$ ) and Yield stress (MPa), c) Yield stress (MPa), d) quadratic/linear approximation, e) polynomial interpolation.

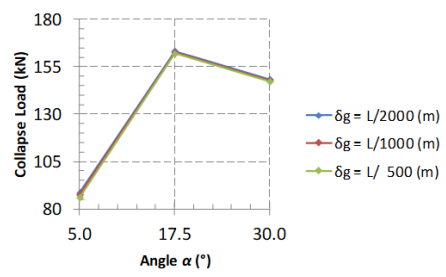

a)

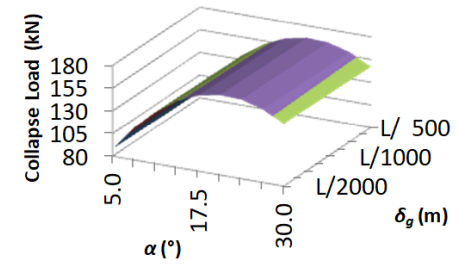

$=$ 80-105 $=105-130 \quad \square$ 130-155 $=155-180$

d)

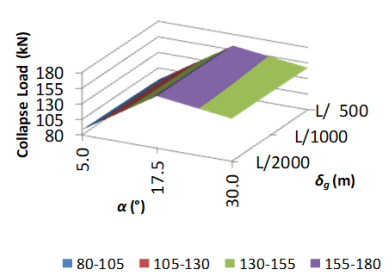

b)

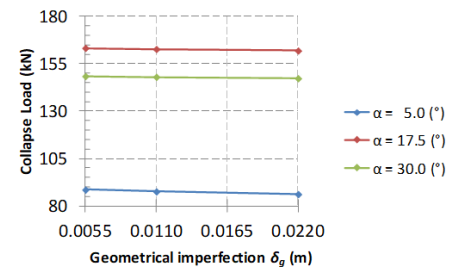

c)

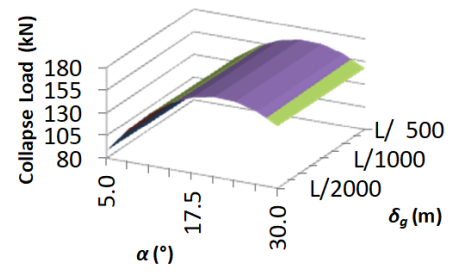

= 80-105 $=105-130=130-155=155-180$

e)

Figure 37 Collapse Load $(\mathrm{kN})$ as a function of the: a) Angle $\left({ }^{\circ}\right)$, b) Angle $\left({ }^{\circ}\right)$ and Geometrical imperfection $(\mathrm{m})$, c) Geometrical imperfection $(\mathrm{m})$, d) quadratic/linear approximation, e) polynomial interpolation.

For each pair of parameters analysed, Table 4 presents the figure in which the results of the analysis are shown, the approximation function and the error range in which the differences between the results obtained in the FEA and the approximation functions are found. The error modules between the approximation function and the FEA are in a similar amount above and below $10 \%$. These results indicate that choosing a quadratic function for the Angle and a linear for the other parameters, without the use of crossed terms, may not be the best choice.

Table 4 Quadratic / linear approximation function.

\begin{tabular}{cccc}
\hline Parameters & Figure & Approximation Function & Error Range \\
\hline$\alpha \times H_{s}$ & $31 \mathrm{~d}$ & $-54.7977+12.2651 \times \alpha-0.2828 \times \alpha^{2}+108.6789 \times H_{s}$ & $-11.15 \%$ to $16.24 \%$ \\
$\alpha \times H_{p}$ & $32 \mathrm{~d}$ & $4.6165+12.0572 \times \alpha-0.2785 \times \alpha^{2}+70.9860 \times H_{p}$ & $-15.30 \%$ to $15.49 \%$ \\
$\alpha \times b_{f}$ & $33 \mathrm{~d}$ & $-77.4611+12.3326 \times \alpha-0.2832 \times \alpha^{2}+484.9467 \times b_{f}$ & $-5.97 \%$ to $6.88 \%$ \\
$\alpha \times t_{f}$ & $34 \mathrm{~d}$ & $-57.8400+12.1983 \times \alpha-0.2808 \times \alpha^{2}+4517.2407 \times t_{f}$ & $-15.66 \%$ to $28.82 \%$ \\
$\alpha \times t_{w}$ & $35 \mathrm{~d}$ & $-39.8588+12.6050 \times \alpha-0.2939 \times \alpha^{2}+5893.7496 \times t_{w}$ & $-7.11 \%$ to $9.06 \%$ \\
$\alpha \times S_{y}$ & $36 \mathrm{~d}$ & $-69.4094+12.4685 \times \alpha-0.2873 \times \alpha^{2}+0.3031 \times S_{y}$ & $-5.39 \%$ to $6.21 \%$ \\
$\alpha \times \delta_{g}$ & $37 \mathrm{~d}$ & $33.3505+12.5037 \times \alpha-0.2881 \times \alpha^{2}-97.9661 \times \delta_{g}$ & $-0.42 \%$ to $6.21 \%$ \\
\hline
\end{tabular}




\subsubsection{Approximation exponential / linear}

Figures 38 to 44 show all cases in which the behavior of the Collapse Load is approximated by an exponential function of the Length and a linear function of the other parameter. Each of the figures is organized as follows: part a) presents the simulated Collapse Load as an exponential function of the Length for different values of the other parameter, part c) presents the behavior as a linear function of the other parameter for different values of the Length, part b) shows a three-dimensional graph of the simulated Collapse Load as a function of the Length and the other parameter simultaneously, part d) shows the same three-dimensional graph of the obtained approximation function and part e) shows another approximation function that will be commented in the section 4.2.3.

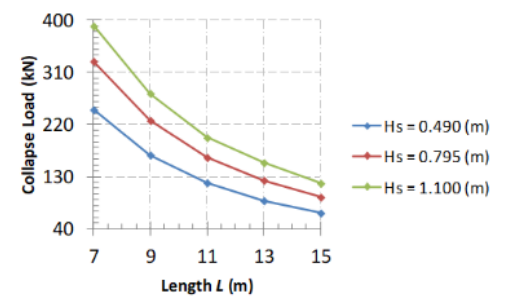

a)

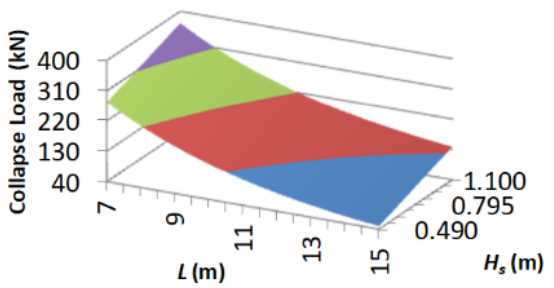

= 40-130 =130-220 $=220-310=310-400$

d)

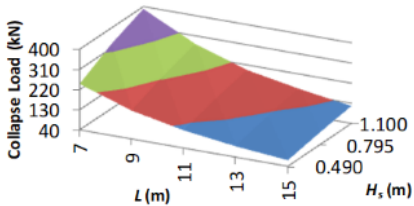

= $40-130=130-220=220-310=310-400$

b)

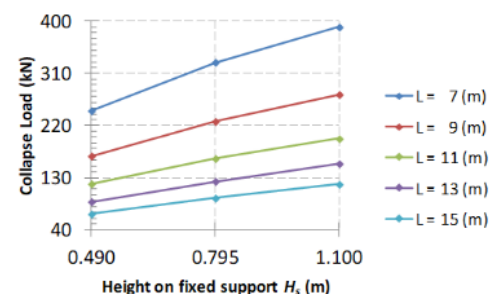

c)

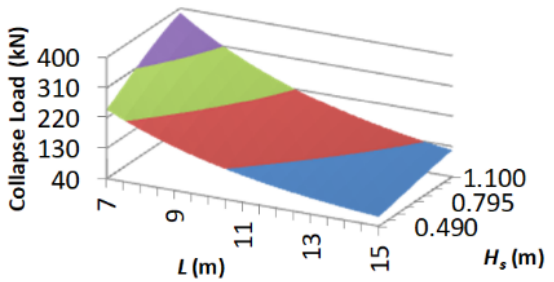

= 40-130 $=130-220=220-310=310-400$

e)

Figure 38 Collapse Load $(\mathrm{kN})$ as a function of the: a) Length $(\mathrm{m}), \mathrm{b})$ Length $(\mathrm{m})$ and Height on fixed support $(\mathrm{m})$, c) Height on fixed support (m), d) exponential/linear approximation, e) crossed terms approximation.

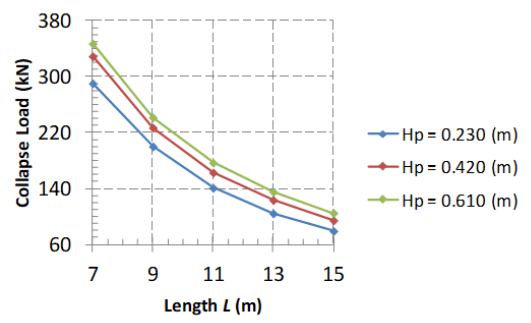

a)

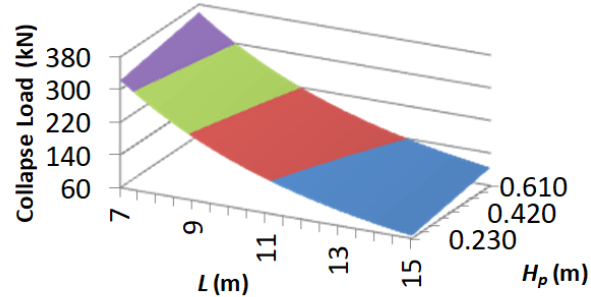

=60-140 | 140-220 =220-300 =300-380

d)

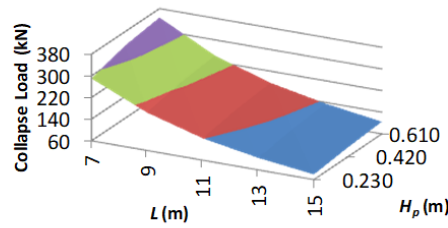

$=60-140=140-220=220-300 \quad=300-380$

b)

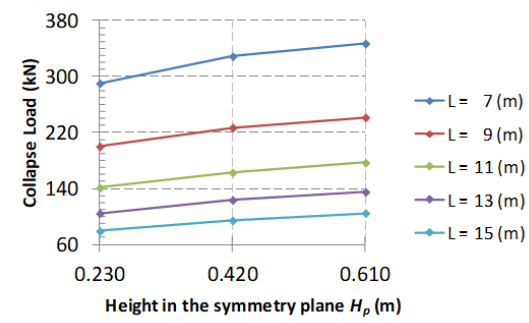

c)

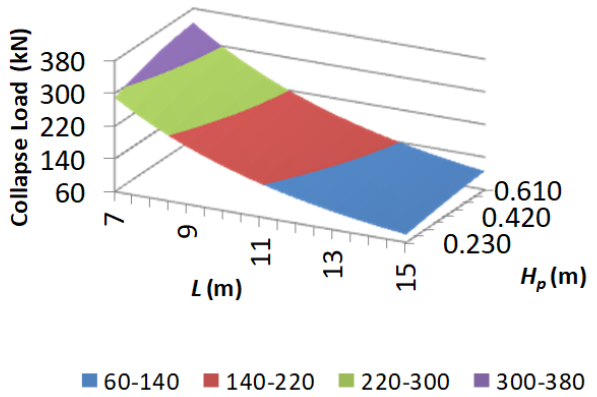

e)

Figure 39 Collapse Load $(\mathrm{kN})$ as a function of the: a) Length $(\mathrm{m}), \mathrm{b})$ Length $(\mathrm{m})$ and Height in the symmetry plane $(\mathrm{m})$, c) Height in the symmetry plane $(\mathrm{m})$, d) exponential/linear approximation, e) crossed terms approximation. 


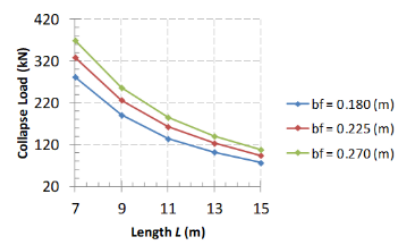

a)

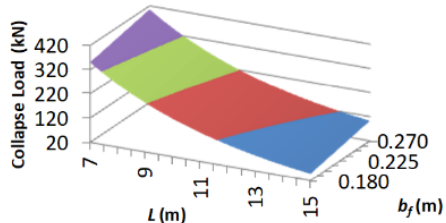

$=20-120=120-220=220-320=320-420$

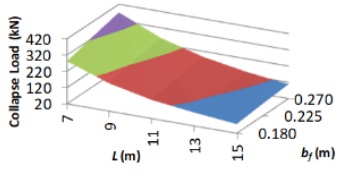

b)

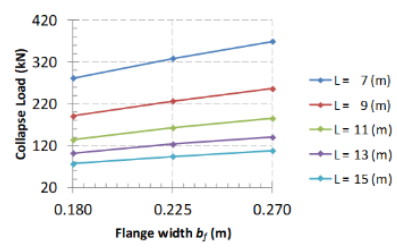

c)

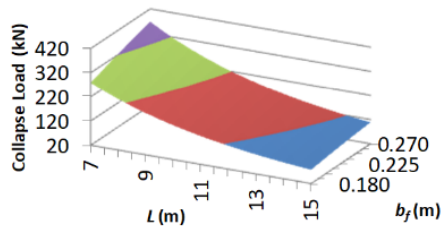

$=20-120=120-220=220-320=320-420$

e)

Figure $\mathbf{4 0}$ Collapse Load (kN) as a function of the: a) Length (m), b) Length (m) and Flange width (m),

c) Flange width $(\mathrm{m})$, d) exponential/linear approximation, e) crossed terms approximation.

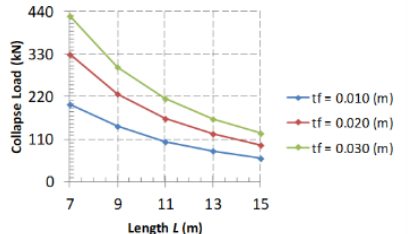

a)

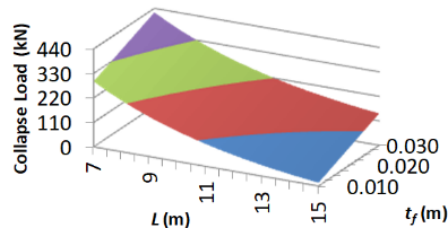

$=0-110=110-220=220-330=330-440$

d)

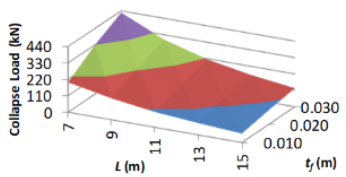

b)

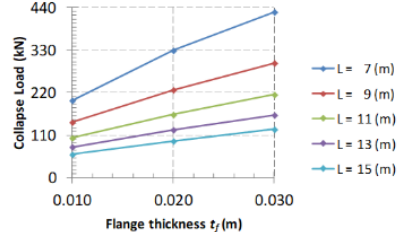

c)

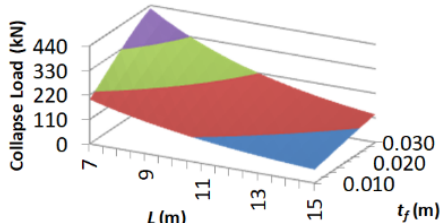

- $0-110=110-220=220-330=330-440$

e)

Figure 41 Collapse Load $(\mathrm{kN})$ as a function of the: a) Length $(\mathrm{m}), \mathrm{b})$ Length $(\mathrm{m})$ and Flange thickness $(\mathrm{m})$, c) Flange thickness $(\mathrm{m})$, d) exponential/linear approximation, e) crossed terms approximation.

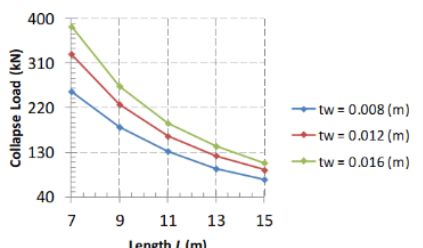

a)

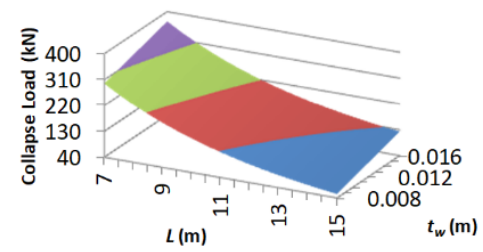

$=40-130=130-220=220-310=310-400$

d)

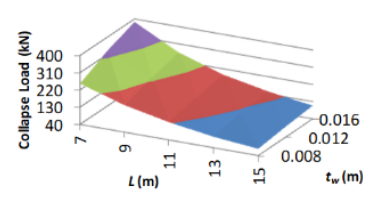

b)

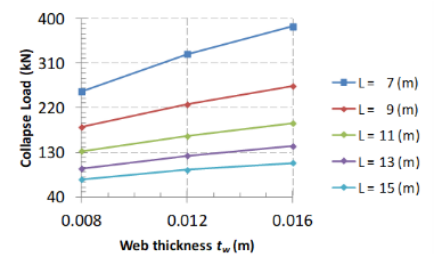

c)

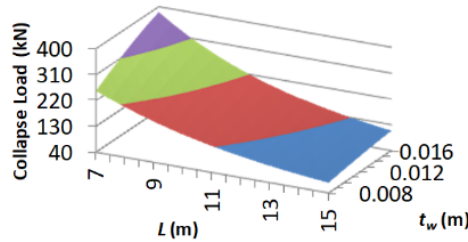

$=40-130=130-220=220-310=310-400$

e)

Figure 42 Collapse Load (kN) as a function of the: a) Length (m), b) Length (m) and Web thickness (m), c) Web thickness $(\mathrm{m}), \mathrm{d}$ ) exponential/linear approximation, e) crossed terms approximation. 


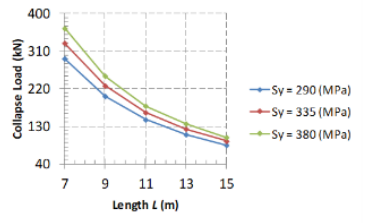

a)

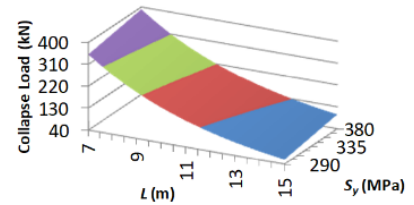

$=40-130=130-220=220-310=310-400$

d)

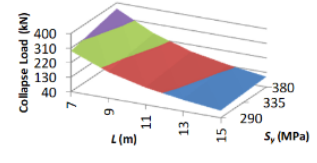

b)

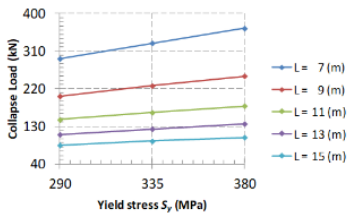

c)

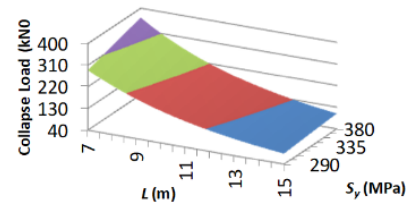

| $40-130=|-130-220 \quad=220-310 \quad|=310-400$

e)

Figure 43 Collapse Load $(\mathrm{kN})$ as a function of the: a) Length $(\mathrm{m}), \mathrm{b})$ Length $(\mathrm{m})$ and Yield stress (MPa), c) Yield stress (MPa), d) exponential/linear approximation, e) crossed terms approximation.

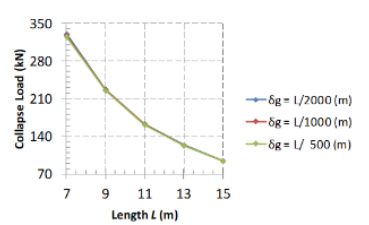

a)

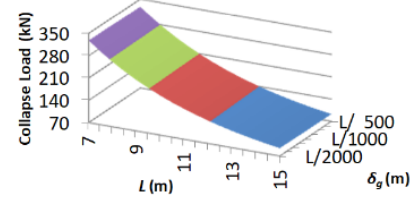

$=70-140=140-210=210-280=280-350$

d)

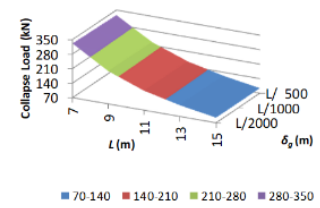

b)

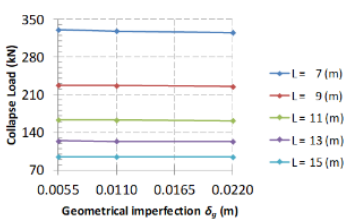

c)

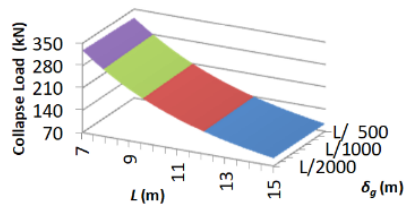

$=70-140=140-210=210-280=280-350$

e)

Figure 44 Collapse Load $(\mathrm{kN})$ as a function of the: a) Length $(\mathrm{m}), \mathrm{b})$ Length $(\mathrm{m})$ and Geometrical imperfection $(\mathrm{m})$,

c) Geometrical imperfection (m), d) exponential/linear approximation, e) crossed terms approximation.

For each pair of parameters analysed, Table 5 presents the figure in which the results of the analysis are shown, the approximation function and the error range in which the differences between the results obtained in the FEA and in the approximation functions are found. Except for one case, all error modules between the approximation function and the FEA are above $10 \%$. This result is a strong indication that choosing an exponential function for the Length and a linear function for the other parameters, without the use of crossed terms, is inadequate.

Table 5 Exponential / linear approximation function.

\begin{tabular}{cccc}
\hline Parameters & Figure & Approximation Function & Error Range \\
\hline$L x H_{s}$ & $38 \mathrm{~d}$ & $-73.9241+1228.3516 \times e^{-0.2123 \times L}+146.0879 \times H_{s}$ & $-27.61 \%$ to $16.34 \%$ \\
$L x H_{p}$ & $39 \mathrm{~d}$ & $-14.6492+1382.7316 \times e^{-0.2117 \times L}+100.3342 \times H_{p}$ & $-16.42 \%$ to $11.11 \%$ \\
$L x b_{f}$ & $40 \mathrm{~d}$ & $-129.6579+1634.6916 \times e^{-0.2119 \times L}+608.2416 \times b_{f}$ & $-37.40 \%$ to $24.35 \%$ \\
$L x t_{f}$ & $41 \mathrm{~d}$ & $-116.3923+1453.5446 \times e^{-0.2051 \times L}+6411.7363 \times t_{f}$ & $-75.31 \%$ to $47.14 \%$ \\
$L x t_{w}$ & $42 \mathrm{~d}$ & $-74.6543+1267.6747 \times e^{-0.2052 \times L}+8731.7787 \times t_{w}$ & $-28.97 \%$ to $17.14 \%$ \\
$L x S_{y}$ & $43 \mathrm{~d}$ & $-135.6542+1562.5285 \times e^{-0.2101 \times L}+0.4404 \times S_{y}$ & $-30.32 \%$ to $20.36 \%$ \\
$L x \delta_{g}$ & $44 \mathrm{~d}$ & $41.6261+1244.0453 \times e^{-0.2095 \times L}-200.8136 \times \delta_{g}$ & $-1.91 \%$ to $1.11 \%$ \\
\hline
\end{tabular}

\subsubsection{Approximation exponential / quadratic}

Figure 45 shows the case in which the behavior of the Collapse Load is approximated by an exponential function of the Length and a quadratic function of the Angle. The figure is organized as follows: part a) presents the simulated Collapse Load as an exponential function of the Length for different values of the Angle, part c) presents the behavior as a quadratic function of the Angle for different values of the Length, part b) shows a three-dimensional graph of the 
simulated Collapse Load as a function of the Length and the Angle simultaneously, part d) shows the same threedimensional graph of the obtained approximation function and part e) shows another approximation function that will be commented in the section 4.2.4.

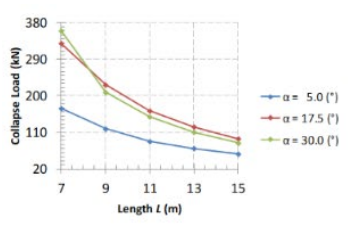

a)

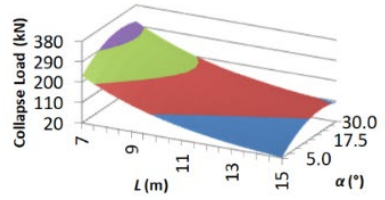

$=20-110=110-200=200-290=290-380$

d)

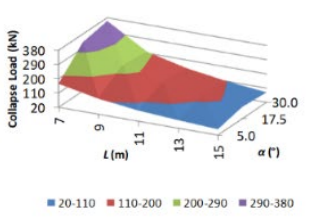

b)
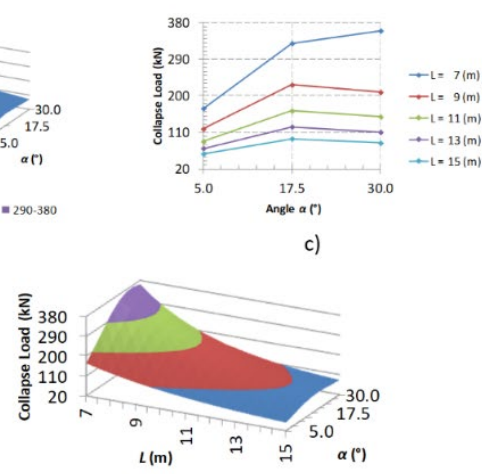

$=20-110=110-200=200-290=290-380$

Figure 45 Collapse Load $(\mathrm{kN})$ as a function of the: a) Length $(\mathrm{m}), \mathrm{b})$ Length $(\mathrm{m})$ and Angle $\left({ }^{\circ}\right)$,

c) Angle $\left({ }^{\circ}\right)$, d) exponential/quadratic approximation, e) crossed terms approximation.

For the pair of parameters analysed, Table 6 presents the figure in which the results of the analysis are shown, the approximation function and the error range in which the differences between the results obtained in the FEA and in the approximation functions are found. The error module between the approximation function and the FEA is much more than $10 \%$. This result is a strong indication that choosing an exponential function for the Length and a quadratic function for the Angle, without the use of crossed terms, is inadequate.

Table 6 Exponential / quadratic approximation function.

\begin{tabular}{ccccc}
\hline Parameters & Figure & Approximation Function & Error Range \\
\hline$L x \alpha$ & $45 \mathrm{~d}$ & $-70.8955+1361.8295 \times e^{-0.2495 \times L}+13.5577 \times \alpha-0.2941 \times \alpha^{2}$ & $-61.60 \%$ to $34.42 \%$ \\
\hline
\end{tabular}

\subsubsection{Global analysis}

Table 7 shows the obtained values for each of the coefficients of the terms used in the approximation functions presented in sections 4.2.2.1 to 4.2.2.4, their means and standard deviations, as well as the ratio between them. For five of the coefficients listed in the table, the ratio between the mean and the standard deviation is above and for six coefficients the ratio is below $0.1(10 \%)$. This is also a clear indication that, in general, the used interpolation functions, without using crossed terms, are not adequate.

Table 7 Term weight of the approximation function.

\begin{tabular}{|c|c|c|c|c|c|c|c|c|c|c|c|}
\hline & $x \cdot e^{L}$ & $\mathrm{e}^{x . L}$ & $x . \alpha$ & $x . \alpha^{2}$ & x. $H_{s}$ & $x . H_{p}$ & $x \cdot b_{f}$ & $x . t_{f}$ & $x . t_{w}$ & $x . S_{y}$ & $x . \delta_{g}$ \\
\hline \multirow[t]{8}{*}{ values } & 1228.352 & -0.212 & 13.558 & -0.294 & 146.088 & 100.334 & 608.242 & 6411.736 & 8731.779 & 0.440 & -200.814 \\
\hline & 1382.732 & -0.212 & 12.265 & -0.283 & 108.679 & 70.986 & 484.947 & 4517.241 & 5893.750 & 0.303 & -97.966 \\
\hline & 1634.692 & -0.212 & 12.057 & -0.279 & 121.724 & 98.938 & 590.501 & 5589.588 & 6847.730 & 0.361 & -122.288 \\
\hline & 1453.545 & -0.205 & 12.333 & -0.283 & 121.505 & 93.126 & 554.228 & 5485.571 & 7091.432 & 0.379 & -101.997 \\
\hline & 1267.675 & -0.205 & 12.198 & -0.281 & 123.900 & 94.351 & 540.109 & 5594.674 & 7454.400 & 0.359 & -76.537 \\
\hline & 1562.529 & -0.210 & 12.605 & -0.294 & 128.162 & 103.474 & 540.796 & 5493.375 & 7819.036 & 0.366 & -78.682 \\
\hline & 1244.045 & -0.210 & 12.469 & -0.287 & 127.215 & 95.120 & 569.595 & 5588.215 & 7178.959 & 0.396 & -69.807 \\
\hline & 1361.830 & -0.250 & 12.504 & -0.288 & 127.219 & 94.858 & 566.363 & 5589.030 & 7672.959 & 0.367 & -84.663 \\
\hline mean $(\bar{x})$ & 1391.925 & -0.214 & 12.499 & -0.286 & 125.561 & 93.898 & 556.848 & 5533.679 & 7336.255 & 0.371 & -104.094 \\
\hline $\begin{array}{c}\text { standard } \\
\text { deviation }(s)\end{array}$ & 149.710 & 0.014 & 0.463 & 0.006 & 10.369 & 9.905 & 37.305 & 510.036 & 820.457 & 0.039 & 42.571 \\
\hline ratio $(s /|\bar{x}|)$ & 0.108 & 0.067 & 0.037 & 0.020 & 0.083 & 0.105 & 0.067 & 0.092 & 0.112 & 0.104 & 0.409 \\
\hline
\end{tabular}


The approximation functions hitherto found can be improved with the use of crossed terms, shown in section 4.2.3, or can be replaced by interpolation functions presented in section 4.2.4.

\subsubsection{Approximation functions with crossed terms}

In order to show how an approximation function can be improved with the use of crossed terms, it was used all cases in which one of the parameters is the Length (sections 4.2.2.3 and 4.2.2.4). Approximation functions with nine terms were used, in which the Collapse Load is given by an exponential function of the Length, whose terms are quadratic functions of the other parameter. The graphs of the new approximation functions using crossed terms are shown in part e) of figures 38 to 44 of section 4.2.2.3 and in part e) of figure 45 of section 4.2.2.4. Table 8 presents the error range of the analyses without the crossed terms, the figure in which the results of the analyses are shown, the approximation function with crossed terms and the new error range in which the differences between the results obtained in the FEA and in the approximation functions are found. All error modules between the approximation function and the FEA are below $5 \%$. These results show a significant improvement in the approximation functions and that they are well suited for obtaining the Collapse Load.

Table 8 Approximation function with crossed terms.

\begin{tabular}{|c|c|c|c|c|}
\hline \multirow[t]{2}{*}{ Parameters } & \multirow{2}{*}{$\begin{array}{c}\begin{array}{c}\text { without crossed } \\
\text { terms }\end{array} \\
\text { Error Range }\end{array}$} & \multicolumn{3}{|c|}{ with crossed terms } \\
\hline & & Figure & Approximation Function & Error Range \\
\hline$L \times \alpha$ & $-61.60 \%$ to $34.42 \%$ & $45 e$ & $\begin{array}{l}\left(37.5704-0.7833 \times \alpha+0.05595 \times \alpha^{2}\right)+ \\
+e^{\left(6.2541+0.03641 \times \alpha+0.0007388 \times \alpha^{2}\right)} \times \\
\times e^{\left(-0.2686+0.1104 \times \alpha-0.0004369 \times \alpha^{2}\right) \times L}\end{array}$ & $-4.48 \%$ to $4.49 \%$ \\
\hline$L \times H_{s}$ & $-27.61 \%$ to $16.34 \%$ & $38 \mathrm{e}$ & $\begin{array}{l}\left(21.3459-9.8882 \times H_{S}+19.0107 \times H_{S}^{2}\right)+ \\
+e^{\left(6.4153+1.2170 \times H_{s}-0.4169 \times H_{S}^{2}\right)} \times \\
\times e^{\left(-0.2562+0.09356 \times H_{S}+0.04403 \times H_{S}^{2}\right) \times L}\end{array}$ & $-1.68 \%$ to $1.68 \%$ \\
\hline$L \times H_{p}$ & $-16.42 \%$ to $11.11 \%$ & $39 e$ & $\begin{array}{l}\left(27.0847+25.3666 \times H_{p}+19.7522 \times H_{p}^{2}\right)+ \\
+e^{\left(6.9497+0.5690 \times H_{p}-0.3929 \times H_{p}^{2}\right)} \times \\
\times e^{\left(-0.2331+0.09312 \times H_{p}-0.08840 \times H_{p}^{2}\right) \times L}\end{array}$ & $-1.00 \%$ to $1.00 \%$ \\
\hline$L x b_{f}$ & $-37.40 \%$ to $24.35 \%$ & $40 e$ & $\begin{array}{l}\left(6.4782+129.9715 \times b_{f}+104.3642 \times b_{f}^{2}\right)+ \\
+e^{\left(6.7577+0.7584 \times b_{f}+3.7369 \times b_{f}^{2}\right)} \times \\
\times e^{\left(-0.3221+0.9399 \times b_{f}-1.9480 \times b_{f}^{2}\right) \times L}\end{array}$ & $-1.87 \%$ to $1.87 \%$ \\
\hline$L x t_{f}$ & $-75.31 \%$ to $47.14 \%$ & $41 \mathrm{e}$ & $\begin{array}{l}\left(1.0516+2192.9476 \times t_{f}-9208.3708 \times t_{f}^{2}\right)+ \\
+e^{\left(5.6203+108.8318 \times t_{f}-1543.7851 \times t_{f}^{2}\right)} \times \\
\times e^{\left(-0.1621-3.6690 \times t_{f}+64.7076 \times t_{f}^{2}\right) \times L}\end{array}$ & $-1.56 \%$ to $1.56 \%$ \\
\hline$L x t_{w}$ & $-28.97 \%$ to $17.14 \%$ & $42 e$ & $\begin{array}{l}\left(-20.5758+7771.0520 \times t_{w}-218719.5822 \times t_{w}^{2}\right)+ \\
+e^{\left(5.6346+184.0293 \times t_{w}-5027.8065 \times t_{w}^{2}\right)} \times \\
\times e^{\left(-0.1272-11.5806 \times t_{w}+393.4179 \times t_{w}^{2}\right) \times L}\end{array}$ & $-1.00 \%$ to $1.00 \%$ \\
\hline$L x S_{y}$ & $-30.32 \%$ to $20.36 \%$ & $43 e$ & $\begin{array}{l}\left(24.1082-0.01060 \times S_{y}+0.0001205 \times S_{y}^{2}\right)+ \\
+e^{\left(5.9708+0.004178 \times S_{y}-0.000002240 \times S_{y}^{2}\right)} \times \\
\times e^{\left(-0.2433+0.0002301 \times S_{y}-0.0000003856 \times S_{y}^{2}\right) \times L}\end{array}$ & $-1.23 \%$ to $1.23 \%$ \\
\hline$L x \delta_{g}$ & $-1.91 \%$ to $1.11 \%$ & $44 \mathrm{e}$ & $\begin{array}{l}\left(42.1091-138.3378 \times \delta_{g}+1671.5931 \times \delta_{g}^{2}\right)+ \\
+e^{\left(7.1510-5.3824 \times \delta_{g}+123.5945 \times \delta_{g}^{2}\right)} \times \\
\times e^{\left(-0.2123+0.4480 \times \delta_{g}-10.0207 \times \delta_{g}^{2}\right) \times L}\end{array}$ & $-1.00 \%$ to $1.00 \%$ \\
\hline
\end{tabular}

\subsubsection{Interpolation}

To show how it is also possible to replace the approximation functions with an interpolation function, the cases in which the Angle is one of the parameters (section 4.2.2.2) were used. As in all the analyses presented here, nine different FEA were performed to obtain the Collapse Load, the corresponding interpolation function is also composed of nine terms. The independent term and products of up to the second order of the involved parameters in each case were used. The graphs of the interpolation functions are shown in part e) of figures 31 to 37 of section 4.2.2.2. Table 9 presents the error range of the analysis without the crossed terms, the figure in which the results of the analysis are shown and the interpolation function with crossed terms. The new error range is not presented because interpolation functions go through all the calculated points, therefore there is no error. 
Table 9 Polynomial interpolation.

\begin{tabular}{|c|c|c|c|}
\hline Parameters & $\begin{array}{c}\text { without crossed } \\
\text { terms }\end{array}$ & & with crossed terms \\
\hline & Error Range & Figure & Interpolation Function \\
\hline$\alpha \times H_{s}$ & $-11.15 \%$ to $16.24 \%$ & $31 \mathrm{e}$ & $\begin{array}{l}-2.2426+3.4170 \times \alpha+52.8670 \times H_{s}-0.09216 \times \alpha^{2}- \\
-11.7927 \times H_{s}^{2}+14.2490 \times \alpha \times H_{s}-0.3081 \times \alpha^{2} \times H_{s}- \\
-3.5731 \times \alpha \times H_{s}^{2}+0.07825 \times \alpha^{2} \times H_{s}^{2}\end{array}$ \\
\hline$\alpha \times H_{p}$ & $-15.30 \%$ to $15.49 \%$ & $32 \mathrm{e}$ & $\begin{array}{l}71.8887+4.0469 \times \alpha-130.7781 \times H_{p}-0.1267 \times \alpha^{2}+ \\
+87.1399 \times H_{p}^{2}+27.5905 \times \alpha \times H_{p}-0.5424 \times \alpha^{2} \times H_{p}- \\
-17.8470 \times \alpha \times H_{p}^{2}+0.3791 \times \alpha^{2} \times H_{p}^{2}\end{array}$ \\
\hline$\alpha \times b_{f}$ & $-5.97 \%$ to $6.88 \%$ & $33 e$ & $\begin{array}{l}-40.5653-1.0722 \times \alpha+435.5458 \times b_{f}+0.05942 \times \alpha^{2}- \\
-496.0185 \times b_{f}^{2}+86.0856 \times \alpha \times b_{f}-2.2804 \times \alpha^{2} \times b_{f}- \\
-114.7575 \times \alpha \times b_{f}^{2}+3.2798 \times \alpha^{2} \times b_{f}^{2}\end{array}$ \\
\hline$\alpha \times t_{f}$ & $-15.66 \%$ to $28.82 \%$ & $34 \mathrm{e}$ & $\begin{array}{l}18.2404+1.5826 \times \alpha+653.2332 \times t_{f}-0.03866 \times \alpha^{2}+ \\
+2570.8812 \times t_{f}^{2}+631.6991 \times \alpha \times t_{f}-14.5011 \times \alpha^{2} \times t_{f}- \\
-4324.8847 \times \alpha \times t_{f}^{2}+102.6601 \times \alpha^{2} \times t_{f}^{2}\end{array}$ \\
\hline$\alpha \times t_{w}$ & $-7.11 \%$ to $9.06 \%$ & $35 e$ & $\begin{array}{l}-12.4707+8.3472 \times \alpha+5384.2985 \times t_{w}-0.2386 \times \alpha^{2}- \\
-137552.1201 \times t_{w}^{2}+211.8357 \times \alpha \times t_{w}+2.9240 \times \alpha^{2} \times t_{w}+ \\
+11093.5809 \times \alpha \times t_{w}^{2}-584.3435 \times \alpha^{2} \times t_{w}^{2}\end{array}$ \\
\hline$\alpha \times S_{y}$ & $-5.39 \%$ to $6.21 \%$ & $36 e$ & $\begin{array}{l}-7.1400+1.7385 \times \alpha+0.1669 \times S_{y}-0.05758 \times \alpha^{2}- \\
-0.0001464 \times S_{y}^{2}+0.03659 \times \alpha \times S_{y}-0.0007682 \times \alpha^{2} \times S_{y}- \\
-0.00001344 \times \alpha \times S_{y}^{2}+0.0000002434 \times \alpha^{2} \times S_{y}^{2}\end{array}$ \\
\hline$\alpha \times \delta_{g}$ & $-0.42 \%$ to $6.21 \%$ & $37 e$ & $\begin{array}{l}-34.6333+12.4262 \times \alpha-231.3904 \times \delta_{g}-0.2874 \times \alpha^{2}- \\
-2027.8656 \times \delta_{g}^{2}+4.4141 \times \alpha \times \delta_{g}+0.04541 \times \alpha^{2} \times \delta_{g}+ \\
+98.5389 \times \alpha \times \delta_{g}^{2}-5.9088 \times \alpha^{2} \times \delta_{g}^{2}\end{array}$ \\
\hline
\end{tabular}

\subsubsection{Approximation function of five parameters}

From the previous analyses, it is observed that the collapse load has a behavior close to the linear concerning five geometric parameters, the Height on fixed support $H_{s}$, the Height in the symmetry plane $H_{p}$, the Flange width $b_{f}$, the Flange thickness $t_{f}$ and the Web thickness $t_{w}$. As each parameter can assume three values, there are 243 possible combinations of these five parameters. To show even more how this analysis can be improved, the 243 FEA are carried out and the results are used to determine the approximation function of these five parameters without the use of crossed terms (Equation 1).

$F=-140.66+71.06 \times H_{s}+81.90 \times H_{p}+122.79 \times b_{f}+4100.1 \times t_{f}+6398.1 \times t_{w}$

Equation 1 leads to an error range of $-35 \%$ to $35 \%$, with frequency distributed according to the histogram of Figure 46 , with a mean value of $-5.0 \%$ and a standard deviation of $14.8 \%$.

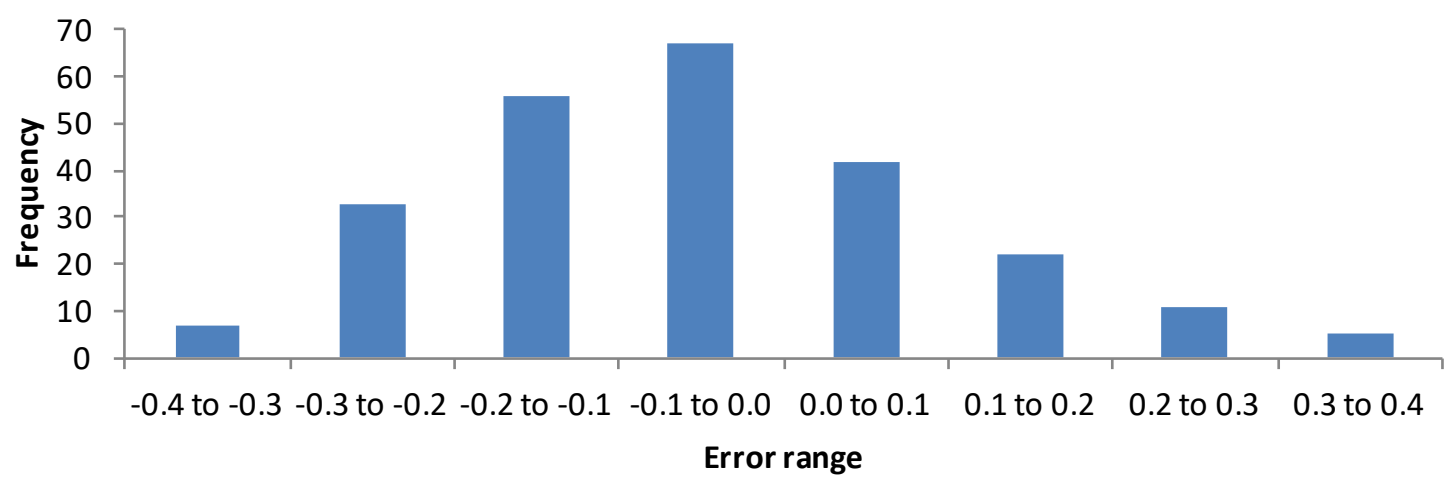

Figure 46 Frequency of results by error percentage range of an approximation function without crossed terms.

A better approximation can be obtained using crossed terms. The approximation function is given by Equation 2 


$$
\begin{gathered}
F=-58.32-15.39 \times H_{s}+22.10 \times H_{p}+155.93 \times b_{f}-719.7 \times t_{f}+1188.9 \times t_{w}+31.95 \times H_{s} \times \\
H_{p}++238.63 \times H_{s} \times b_{f}+1378.6 \times H_{s} \times t_{f}+2487 \times H_{s} \times t_{w}+90.6 \times H_{p} \times b_{f}+1683 \times H_{p} \times t_{f}+ \\
3717 \times H_{p} \times t_{w}++2326 \times b_{f} \times t_{f}-3816 \times b_{f} \times t_{w}+195070 \times t_{f} \times t_{w}
\end{gathered}
$$

Equation 2 leads to an error range of $-23 \%$ to $23 \%$, with frequency distributed according to the histogram of Figure 47 , with a mean value of $-3.9 \%$ and standard deviation of $11.8 \%$.

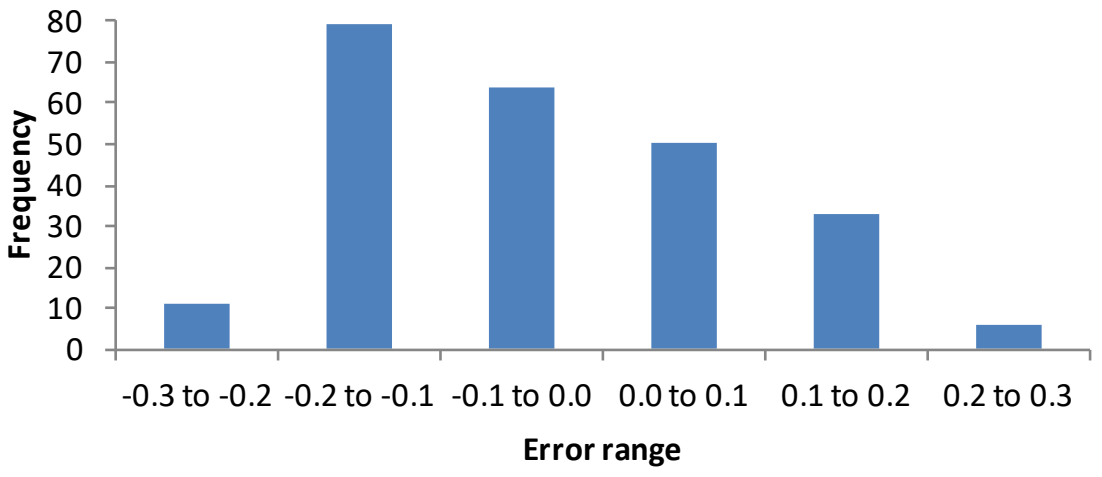

Figure 47 Frequency of results by error percentage range of an approximation function with crossed terms.

\section{CONCLUSIONS}

The objectives of this work have been achieved. Initially, the ideal FE edge size was determined to perform the analyses with the guarantee of the quality of the results. In the general case, the FE edge size of $30 \mathrm{~mm}$ was used. For a Web thickness of $8 \mathrm{~mm}$, a FE edge size of $20 \mathrm{~mm}$ was used and for a Flange thickness of $10 \mathrm{~mm}$, FE edge size of $25 \mathrm{~mm}$ was used. The results to determine the ideal number of loading sub-steps have not been presented. They are only the information of the simulation time for each number of loading sub-steps used. The minimum time condition was reached for 10 loading sub-steps.

Then, a large number of simulations for different parameters combinations were carried out to determine the influence of each one of them on the Collapse Load of the I-section tapered beam. With this information, various graphs were drawn up which made it possible to observe and to quantify the influence of each parameter. It was then found that the parameters Height on fixed support, Height in the symmetry plane, Flange width, Flange thickness, Web thickness, Global geometrical imperfection and Yield stress linearly influence the response, while the Angle influences quadratically and the Length logarithmically. The influence of the combination of two parameters, which individually influence linearly on the Collapse Load, can be represented by an approximation function without using crossed terms with errors of less than $10 \%$. The joint influence of two parameters without the use of crossed terms, when one of them has quadratic or logarithmic individual influence, led to major errors. This discrepancy between the approximation functions and the FEA was improved to values below $5 \%$ when using crossed terms. Finally, the approximation function for five geometric parameters with individual linear influence was presented. Without the use of crossed terms the error range was from $-35 \%$ to $35 \%$, but with the use of first-order crossed terms the error was reduced to the range of $-23 \%$ to $23 \%$

Obtaining approximation functions with minor errors without first carrying out all 295245 PA is irrelevant, as it would be expensive and in the future modified by additional information. However, the results obtained so far show that this research must be continued and that after the completion of all PAs, an ANN and an empirical approximation equation with very acceptable errors will probably be obtained.

\section{FUTURE RESEARCHES}

Once validated the FE model and the influence of the various parameters on the Collapse Load is evaluated, the authors aim to run the PA with all possible combinations of values presented in Table 1, and then study the influence of several input (independent) variables on the Elastic Buckling and Collapse Load. Lastly, the PA-based data will be used to 
develop an ANN-based and empirical equations to accurately and efficiently predict the Buckling or Collapse Load of any member within the variable ranges presented in Table 1.

\section{Acknowledgment}

The authors would like to thank the Laboratory of Applied and Computational Mechanics of the Department of Mechanical Engineering of the São Carlos Engineering Scholl of the University of São Paulo and the company Tal Projecto - Projetos, Estudos e Serviços de Engenharia, Lda, Lisbon, Portugal for the availability of computational equipment and the license of the used software. As well as thanking several of its members for the rich discussions held in the development of this work.

Author's Contributions: Conceptualization, M Abambres, TP Ribeiro; Formal analysis, E Massaroppi Jr, TC Zampaolo; Resources, E Massaroppi Jr; Software, E Massaroppi Jr; Writing - original draft, E Massaroppi Jr, M Abambres, TP Ribeiro; Writing - review \& editing, E Massaroppi Jr, TP Ribeiro.

Guest Editors: Volnei Tita and Nicholas Fantuzzi.

\section{References}

Adeli, H. (2001). Neural networks in civil engineering: 1989-2000, Computer-Aided Civil and Infrastructure Engineering, 16(2), 126-142.

Adeli, H., Park, H.S. (1995). Optimization of space structures by neural dynamics, Neural Networks, 8(5), 769-781.

Adeli, H., Yeh, C. (1989). Perceptron Learning in Engineering Design, Computer-Aided Civil and Infrastructure Engineering, 4(4), 247-256.

AISC - American Institute of Steel Construction (2010). Specification for Structural Steel Buildings (ANSI/AISC 360-10), AISC, Chicago, USA

Altair HyperWorks, 2011, "Practical Aspects of Finite Element Simulation - A Student Guide”, Altair Engineering, Inc., Michigan, USA.

Ansys Inc. (2014). ANSYS APDL (Mechanical), release 15.0, Canonsburg, PA.

Asgarian, B., Soltani, M. (2011). Lateral-Torsional Buckling of Non-Prismatic Thin-Walled Beams with Non-Symmetric Cross Section, Procedia Engineering, 14 (Proceedings of the Twelfth East Asia-Pacific Conference on Structural Engineering and Construction - EASEC12), pp. 1653-64

Balduzzi, G., Morganti, S., Auricchio, F., Reali, A. (2017). Non-prismatic Timoshenko-like beam model: Numerical solution via isogeometric collocation, In Computers \& Mathematics with Applications, 74(7), pp. 1531-1541.

Banu, P.S.N., Rani, S.D. (2016). Knowledge-based artificial neural network model to predict the properties of alpha+ beta titanium alloys, Journal of Mechanical Science and Technology 30 (8), 3625-3631.

Bedynek, A., Real, E., Mirambell, E. (2013). Tapered plate girders under shear: Tests and numerical research, 46(January), pp. 350-58

BSK 99 (2003). Swedish design rules for steel structures, Boverket, Karlskrona.

CEN - Comité Européen de Normalisation (2005). Eurocode 3: Design of steel structures. Part 1-1: General rules and rules for buildings (EN 1993-1-1), Brussels

CEN - Comité Européen de Normalisation (2006). Eurocode 3. Design of steel structures. Part 1-5: Plated structural elements (EN 1993-1-5), Brussels

Chuang, P.H., Goh, A.T.C., Wu, X. (1998). Modeling the capacity of pin-ended slender reinforced concrete columns using neural networks, Journal of Structural Engineering, 124(7), 830-8. 
ECCS (1984). Ultimate limit state calculation of sway frames with rigid joints, Technical Committee 8 - Structural Stability Technical Working Group 8.2, Publication No. 33, Paris.

Efstathiadesa, C., Baniotopoulosa, C.C., Nazarkob, P., Ziemianskib, L., Stavroulakisc, G.E. (2007). Application of neural networks for the structural health monitoring in curtain-wall systems, Engineering Structures, 29(12), 3475-84.

Flood, I. (2008). Towards the next generation of artificial neural networks for civil engineering, Advanced Engineering Informatics, 22(1), 4-14.

Gandomi, A.H., Yun, G.J., Alavi AH (2013). An evolutionary approach for modeling of shear strength of RC deep beams, Materials and Structures, 46(12), 2109-2119.

Ghadban, A.A., Al-Rahmani, A.H., Rasheed, H.A., Albahttiti, M.T. (2017). Buckling of Nonprismatic Column on Varying Elastic Foundation with Arbitrary Boundary Conditions, Mathematical problems in engineering, Volume 2017, 1-14.

Guzelbey, I.H., Cevikb, A., Gogus, M.T. (2006). Prediction of rotation capacity of wide flange beams using neural networks, Journal of Constructional Steel Research, 62(10), pp. 950-61

Jung, S., Ghaboussi, J. (2006). Neural network constitutive model for rate-dependent materials, Computers \& Structures, 84(15-16), 955-963.

Kim, H., Jang, G.-W. (2017). Higher-order thin-walled beam analysis for axially varying generally shaped cross sections with straight cross-section edges, Computers \& Structures, 189(September), 83-100.

Lee, J., Lee, B. (2018). Elastica and buckling loads of nonlinear elastic tapered cantilever columns, Engineering Solid Mechanics, $6(1), 39-50$.

Lu, Y., Ye, L., Su, Z., Zhou, L., Cheng, L. (2009). Artificial Neural Network (ANN)-based Crack Identification in Aluminum Plates with Lamb Wave Signals, Journal of Intelligent Material Systems and Structures, 20(1), 39-49.

Marques, L., Taras, A., Silva, L.S., Greiner, R., Rebelo, C. (2012). Development of a consistent buckling design procedure for tapered columns, Journal of Constructional Steel Research, 72(May), 61-74.

Masri, S.F., Smyth, A.W., Chassiakos, A.G., Caughey, T.K., Hunter, N.F. (2000). Application of neural networks for detection of changes in Nonlinear systems, Journal of Engineering Mechanics, 126(7), 666-676.

Min, J., Park, S., Yun, C.-B., Lee, C.-G. (2012). Impedance-based structural health monitoring incorporating neural network technique for identification of damage type and severity, Engineering Structures, 39(June), 210-220.

Mohri, F., Meftah, S.H., Damil, N. (2015). A large torsion beam finite element model for tapered thin-walled open cross section beams, Engineering Structures, 99 (September), pp. 132-48

Mukherjee, A., Deshpande, J.M., Anmala, J. (1996), Prediction of buckling load of columns using artificial neural networks, Journal of Structural Engineering, 122(11), 1385-7.

Nazari, A., Rajeev, P., Sanjayan, J.G. (2015), Offshore pipeline performance evaluation by different artificial neural networks approaches, Measurement, 76 (December), pp. 117-28

Oeser, M., Freitag, S. (2016). Fractional derivatives and recurrent neural networks in rheological modelling - part I: Theory, International Journal of Pavement Engineering, 17(2), 87-102.

Papadrakakis, M., Lagaros, N.D. (2016) Reliability-based structural optimization using neural networks and Monte Carlo simulation, Computer Methods in Applied Mechanics and Engineering, 191(32), 3491-3507.

Papp, F. (2016). Buckling assessment of steel members through overall imperfection method, Engineering Structures, 106 (January), pp. 124-36

SA - Standards Australia (2016). Australian standard: Steel Structures, AS 4100-1998 (R2016), Sydney.

Sharifi, Y., Tohidi, S. (2014). Lateral-torsional buckling capacity assessment of web opening steel girders by artificial neural networks - elastic investigation, Frontiers of Structural and Civil Engineering, 8(2), 167-177.

Sheidaii, M.R., Bahraminejad, R. (2012). Evaluation of compression member buckling and post-buckling behaviour using artificial neural network, Journal of Constructional Steel Research, 70(March), 71-77.

Sourmail, T., Bhadeshia, H.K.D.H., MacKay, D.J.C. (2002). Neural network model of creep strength of austenitic stainless steels, Materials Science and Technology, 18(June), 655.663. 
Tohidi, S., Sharifi, Y. (2015). Neural networks for inelastic distortional buckling capacity assessment of steel I-beams, ThinWalled Structures, 94 (September), pp. 359-371

Tohidi, S., Sharifi, Y. (2016). Load-carrying capacity of locally corroded steel plate girder ends using artificial neural network, Thin-Walled Structures, 100 (March), pp. 48-61

Trahair, N.S. (2014). Bending and buckling of tapered steel beam structures, Engineering Structures, 59 (February), pp. $229-37$

Wang, Y.B., Li, G.Q., Chen SW (2012). Residual stresses in welded flame-cut high strength steel H-sections, Journal of Constructional Steel Research, 79(December), 159-165.

Xu, J., Zhao, J., Wang, W., Liu, M. (2013). Prediction of temperature of tubular truss under fire using artificial neural networks, Fire Safety Journal, 56 (February), pp. 74-80

Zhang, B.-H., Guo, Y.-L., Dou, C. (2013). Ultimate bearing capacity of asymmetrically double tapered steel columns with tubular cross-section, Journal of Constructional Steel Research, 89 (October), pp. 52-62

Zhang, L., Tong, G.S. (2008). Lateral buckling of web-tapered I-beams: A new theory, Journal of Constructional Steel Research, 64(12), 1379-93. 